\title{
WestVirginiaUniversity
}

THE RESEARCH REPOSITORY @ WVU

Graduate Theses, Dissertations, and Problem Reports

2005

\section{The relation of psychopathic characteristics and malingering of PTSD}

\author{
Elizabeth Ann Tyner \\ West Virginia University
}

Follow this and additional works at: https://researchrepository.wvu.edu/etd

\section{Recommended Citation}

Tyner, Elizabeth Ann, "The relation of psychopathic characteristics and malingering of PTSD" (2005). Graduate Theses, Dissertations, and Problem Reports. 4202.

https://researchrepository.wvu.edu/etd/4202

This Thesis is protected by copyright and/or related rights. It has been brought to you by the The Research Repository @ WVU with permission from the rights-holder(s). You are free to use this Thesis in any way that is permitted by the copyright and related rights legislation that applies to your use. For other uses you must obtain permission from the rights-holder(s) directly, unless additional rights are indicated by a Creative Commons license in the record and/ or on the work itself. This Thesis has been accepted for inclusion in WVU Graduate Theses, Dissertations, and Problem Reports collection by an authorized administrator of The Research Repository @ WVU. For more information, please contact researchrepository@mail.wvu.edu. 
The Relation of Psychopathic Characteristics and Malingering of PTSD

\author{
Elizabeth Ann Tyner
}

Thesis submitted to the

Eberly College of Arts and Sciences at West Virginia University

in partial fulfillment of the requirements for the degree of

\author{
Master of Science \\ in \\ Clinical Psychology
}

\author{
William Fremouw, Ph.D., Committee Chairperson \\ Barry Edelstein, Ph.D. \\ Martin Boone, Ph.D. \\ Julie Hicks Patrick, Ph.D.
}

\author{
Department of Psychology \\ Morgantown, West Virginia \\ 2005
}

Keywords: Psychopathy, Malingering, PTSD 


\section{ABSTRACT \\ The Relation of Psychopathic Characteristics and Malingering of PTSD \\ Elizabeth Ann Tyner}

Clinical lore suggests that psychopaths should be successful malingers, yet empirical evidence is inconclusive. To further investigate the relation of psychopathy and malingering, 56 undergraduate males were classified into three groups based on responses to one trauma screener (Posttraumatic Stress Diagnostic Scale; PDS, Foa, Cashman, Jaycox \& Perry, 1997) and one psychopathy screener (Psychopathic Personality Inventory: Short Form; PPI: SF, Lilienfeld \& Andrews, 1996). This multimodal simulation study examined the ability of participants high and low in psychopathic characteristics to successfully malinger PTSD. Contrary to predictions, results indicated that individuals high in psychopathic characteristics were not better at convincing raters of a PTSD diagnosis, nor were they better at producing valid PTSD profiles on self-report measures. Individuals high in psychopathic characteristics were not more confident in their ability to avoid detection of malingering. Results from this study failed to demonstrate that individuals high in psychopathic characteristics are more successful malingerers. 
To dad-

My life mentor and shining star. 


\section{ACKNOWLEDGMENTS}

Words of gratitude and thanks are insufficient to recognize the efforts and dedication of all those who have contributed to the completion of this thesis; however, I would like to acknowledge those individuals.

First, I would like to thank my advisor, Bill Fremouw, for his wisdom and guidance throughout this thesis and also my graduate school journey. His energy and enthusiasm ensured the timely completion of this project. He inspires me to strive for the highest academic excellence.

In addition, I thank the members of my committee-Barry Edelstein, Martin Boone, Stanley Cohen, and Julie Patrick. All provided invaluable assistance throughout this project.

I also thank the undergraduate research assistants-Jennifer Born, James Cook, Stephanie Dismuke, Ashlee Forte, Heather Perkins, Kelly Petersen, David Plantz, Laura Spengler, and Adam Wilson-for all of their hard work and dedication.

Warm thanks to my friends Brian Ayotte, Julie Strunk, and Mirari Elkoro for their helpful advice and suggestions.

In addition, I thank Scott Lilienfeld and Jonathan Davidson for their helpfulness and guidance regarding their assessment measures used in this thesis study.

To my wonderful family- mom, Molly, Jamey and Drew-you have taught me to be persistent and to follow my dreams. Your steadfast love and support have provided me with the confidence to take risks. Thank you.

To my boyfriend Blake, thank you for your support and patience. You have brightened my life with love and happiness. 
Table of Contents

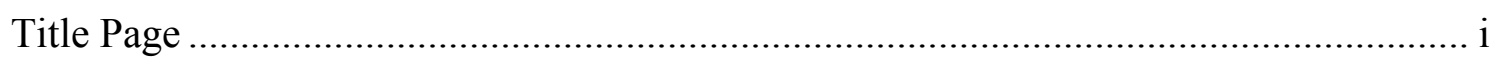

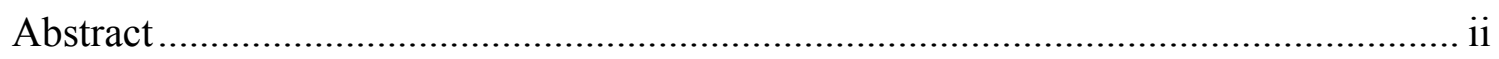

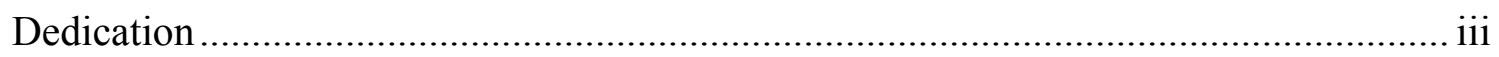

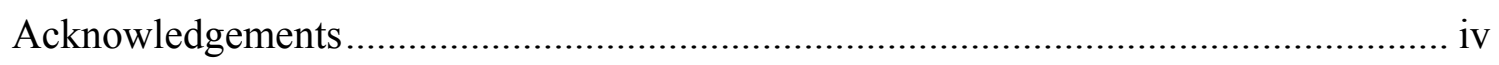

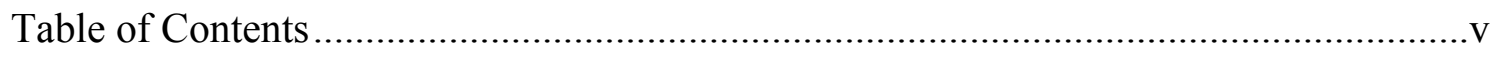

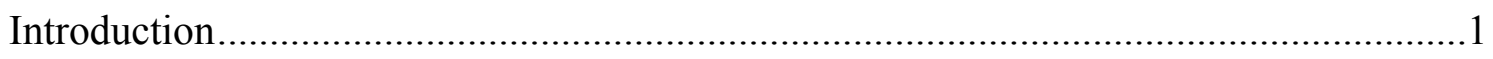

Brief Historical Development of Psychopathy ................................................

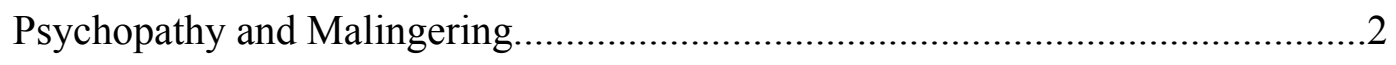

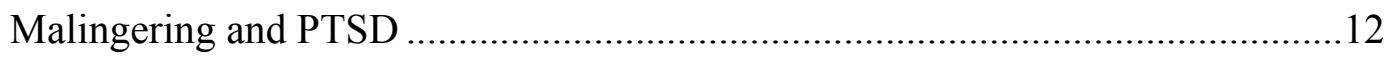

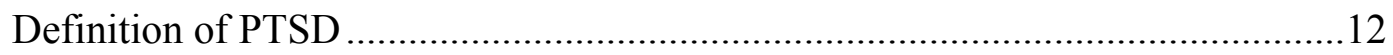

DSM-IV diagnostic criteria.......................................................... 13

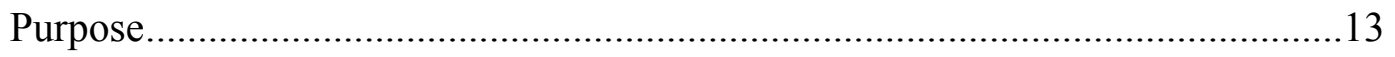

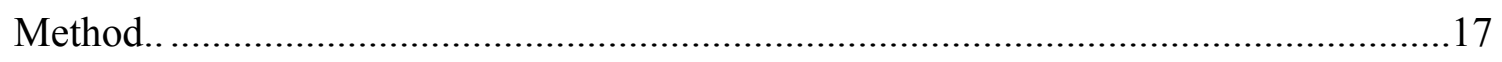

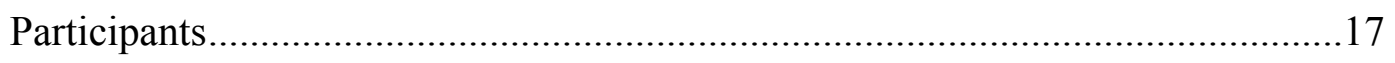

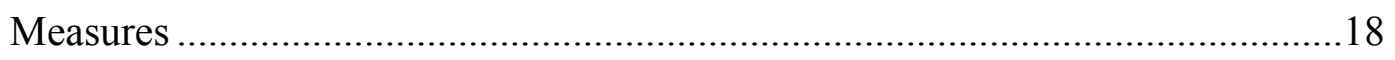

Posttraumatic Stress Diagnostic Scale _................................................18

Psychopathic Personality Inventory: Short Form ...................................19

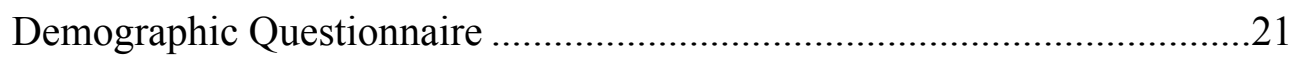

Detailed Assessment of Posttraumatic Stress ........................................21

The Structured Interview for PTSD Scale .............................................23

Administrator Rating of Believability Questionnaire ...............................23

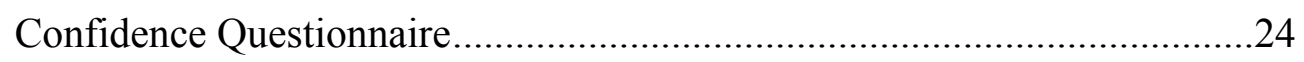


Future Likelihood of Lying Questionnaire ............................................24

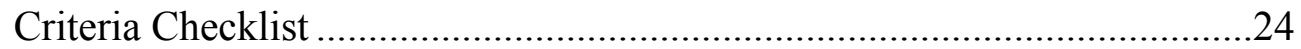

Contact Information Form ..........................................................24

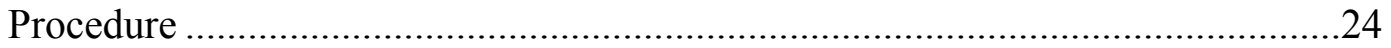

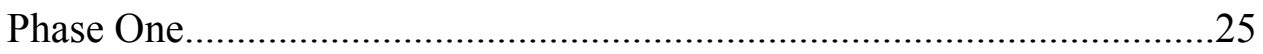

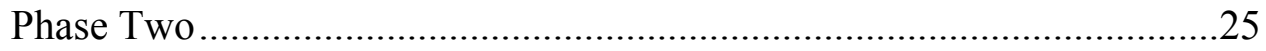

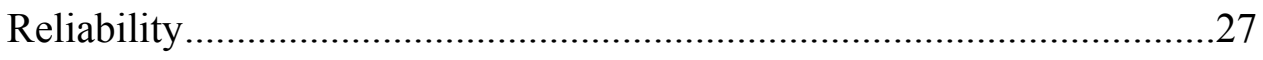

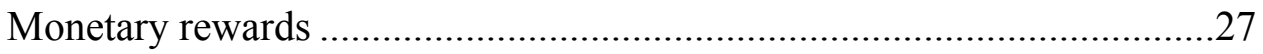

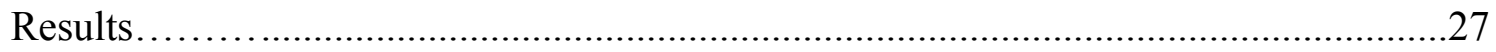

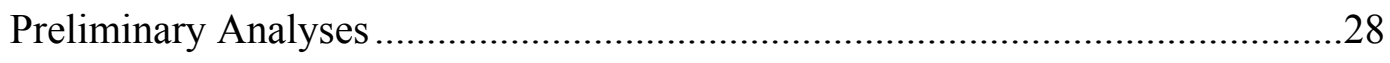

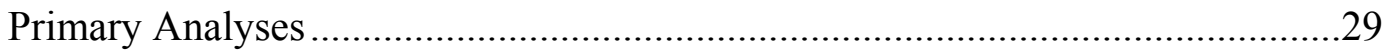

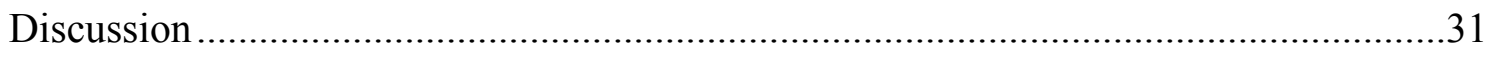

Psychopathy and Malingering on Administrator Ratings ..................................32

Psychopathy and Malingering on the Self-Report Measure ................................33

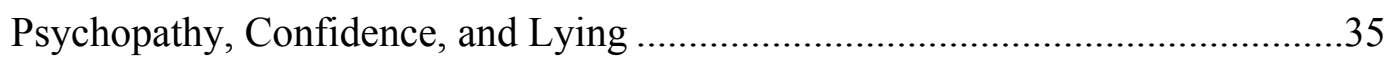

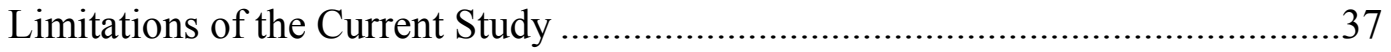

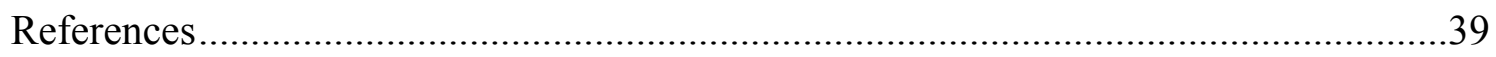

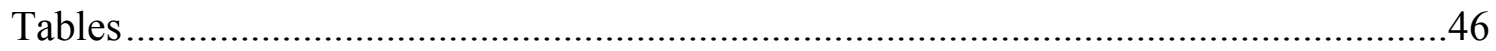

Table 1 Cleckley's Sixteen Characteristics of Psychopaths ..............................46

Table 2 DSM-IV-TR Criteria for Antisocial Personality Disorder .....................47

Table 3 Psychopathy Checklist-Revised (PCL-R) Items ..................................48

Table 4 Demographics of Participants by Group.............................................49

Table 5 Administrator Measures: SIP and ARB Total Score by Group ................52 
Table 6 Self-Report Measure: DAPS Total Score and Subscale Score by Group.53

Table 7 Number of Participants That Successfully Avoided Detection of

Malingering PTSD on the DAPS by Group.....................................................54

Table 8 Self-Report Interpersonal Measures: CQ and FLL Score by Group ........55

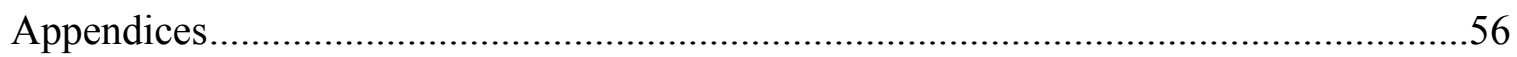

Appendix A Recruitment Flyers and Sign-Up Sheets ......................................56

Appendix B Phase One Measure ...................................................................61

Appendix C Phase Two Instructions and Measures ........................................63

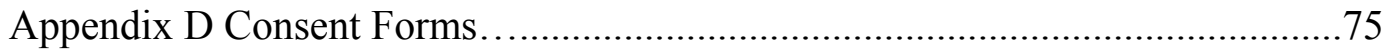

Appendix E Debriefing Forms .......................................................... 81

Appendix F Participation Record and Payment Invoice ....................................84

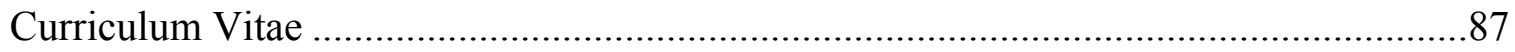


The Relation of Psychopathic Characteristics and Malingering of PTSD

Approximately one percent of the general population and $15-25 \%$ of the prison population is estimated to be psychopaths (Hare, 1996). Although these figures may not seem impressive, the negative impact psychopaths have on society is concerning. Many psychopaths are institutionalized, yet other psychopathic individuals reside freely, preying on society by creating physical, emotional, and economic damage (Hare, 1996). The construct of psychopathy consists of interpersonal characteristics (e.g., deceitfulness, manipulativeness, and narcissism) and deviant, antisocial behaviors. Psychopathy has been an increasing focus for research and clinical attention in the past three decades; its etiology, terminology, and relevance both in forensic practice and legal settings continue to be debated.

\section{Brief Historical Development of Psychopathy}

In the 1800s, Phillipe Pinel observed some of his institutionalized patients behaving violently and impulsively without any indication of severe psychopathology. Pinel labeled this concept maine sans delire (insanity without delirium). This was the first formal classification of antisocial behaviors as a psychological problem. Throughout the $19^{\text {th }}$ century, alternative labels of behavior surfaced such as moral insanity and psychopathic inferiority, coined by Prichard and Koch, respectively, bringing rise to a construct involving antisocial behaviors and a lack of morality (Arrigo \& Shipley, 2001). Much later in 1941, Cleckley published the first edition of The Mask of Sanity. This publication presented a personality-based description of sixteen characteristics describing the same construct, which he labeled psychopathy (Cleckley, 1988, $5^{\text {th }}$ ed., p. 337-338; see Table 1).

The first and second editions of the Diagnostic and Statistical Manual of Mental Disorders (DSM-I, DSM-II; American Psychiatric Association (APA), 1952; 1968) recognized 
the "sociopathic" and "antisocial" personality, analogous to Cleckley's definition of psychopathy. With the DSM-III and the DSM-III-R (APA, 1980; 1987) came a new label, Antisocial Personality Disorder (APD). This disorder was based less on personality traits and more on antisocial behaviors, such as aggression and stealing. The most recent editions (DSM-IV and DSM-IV-TR (APA, 1994; 2000)) defined APD almost exclusively by criminal behavior with only a small focus on an interpersonal dimension (Cale \& Lilienfeld, 2003) (See Table 2).

Using a combination of Cleckley's personality description of psychopathy and the DSM antisocial behavioral description of APD, Hare developed the Psychopathy Checklist in 1980 and a revised edition (PCL-R) in 1991 (See Table 3). This 20-item semi-structured interview is now considered the "gold standard" for the definition and assessment of psychopathy; it takes approximately two hours to complete, yields a total score, and ultimately a dichotomous rating of psychopathy (i.e., presence or absence). The PCL-R requires the clinician to complete an extensive record review and gather collateral information on each individual. Clinicians must be trained in order to administer the PCL-R. This thorough assessment procedure is ideal but not always practical due to time and resource requirements.

The PCL-R defines psychopathy on two dimensions or factors. Factor 1 is a group of traits including manipulativeness, callousness, and lack of remorse. Factor 2 consists of antisocial, deviant behaviors (Hare, 1991). These factors have become known as primary (Type I) and secondary (Type II) psychopathy. This two-dimension system, as defined by Hare, is the most comprehensive classification method because it accounts for all aspects of the construct. Psychopathy and Malingering

The DSM-IV (APA, 2000) description of APD states that individuals with this diagnosis have a tendency to repeatedly malinger. The currently accepted PCL-R definition of psychopathy 
(Hare, 1991) is comprised of two factors. The first factor addresses personality traits. The second factor focuses on antisocial behaviors, similar to those presented in the $D S M-I V-T R$ (APA, 2000) definition of APD. Some examples of these behaviors (which are items on the PCL-R) are: impulsivity, poor behavioral controls, and need for stimulation. Because of the overlap between APD and psychopathy, a valid assumption is that psychopaths, similar to individuals with APD, are likely to engage in repeated malingering.

Malingering is defined in the DSM-IV as "the intentional production of false or grossly exaggerated physical or psychological symptoms, motivated by external incentives" (APA, 2000, p. 739). Moreover, the $D S M-I V$ lists four warning signs to consider during a malingering evaluation: a) medicolegal scenarios, b) incongruence between symptom presentation and rater observation, c) noncompliance, and d) presence of APD.

Although it is nearly impossible to determine the exact prevalence of malingering, an estimation was derived from a survey administered to 221 forensic psychologists. These experts, whom evaluated 100 or more individuals, retrospectively estimated the occurrence of malingering. Malingering, defined as feigning mental illness, cognitive impairment, or medical syndromes, was reported to be present in $17.4 \%$ of forensic and $7.16 \%$ of nonforensic evaluations (Rogers, Salekin, Sewell, Goldstein, \& Leonard, 1998). Because many psychological symptoms occur covertly, malingering is often difficult to assess and even more problematic to confirm (Rogers, 1997). Recently, the assessment and diagnosis of malingering has been the focus of much research.

Rogers (1990a, 1990b) developed three models for classifying and explaining malingering: pathogenic, adaptational, and criminological. The first model attributes malingering to pathological problems, suggesting that an individual with psychological problems will first 
malinger, but later a true psychological disorder will surface. In other words, malingering emerges in the beginning stages of the development of mental illness, which is later replaced with true psychopathology (the "mad" explanation). The adaptational model explains malingering to stem from a cost-benefit analysis. The individual malingers in an attempt to either avoid negative consequences (e.g., incarceration) or gain something (e.g., monetary reward from a civil litigation case). Of particular interest in this study is the third model. This criminological model provides the best explanation for malingering by psychopaths, especially in forensic settings. According to this model, psychopaths, by definition, are "bad" people who innately and selfishly malinger without guilt or remorse (the "bad" explanation).

Although psychopathy does not automatically indicate malingering (Cunnien, 1997), Rogers' criminological model of malingering (1990a, 1990b) suggests that people high in psychopathic characteristics are expected to be more likely to malinger and engage more frequently in this behavior, due to their inherently "bad" genetic makeup. Given this predisposition for "badness" and the presence of manipulative and deceitful personality traits, psychopaths theoretically should be more likely to malinger, particularly when involved in a forensic situation.

Researchers have only addressed the relation between psychopathy and malingering in the past twenty years. Results from most of these studies do not support the clinical lore that psychopaths are more successful malingerers. It is unclear if psychopaths are better than nonpsychopaths at avoiding detection of malingering.

In an unpublished study, Kropp (1992) was the first to examine the direct relation between psychopathy and malingering. Participants were one hundred male inmates lacking severe psychopathology, defined as "psychologically knowledgeable" as all were enrolled in 
programs for "treatable disorders" (e.g., anger management, sex offender treatment, and substance abuse treatment). Participants were divided into psychopathic and nonpsychopathic groups based on responses to the Psychopathy Checklist-Screening Version (PCL-SV; Hart, Hare, \& Forth, 1994). These results were corroborated with the APD portion of the Structured Clinical Interview for the DSM-III-R (SCID; Spitzer, Williams, \& Gibbons, 1987). Subsequently, participants were randomly assigned to the simulation (malinger mental illness) condition or to the honest condition ( 25 participants in each of the four conditions).

Simulators received instructions to feign a severe mental illness with the goal of being believable and to remain at the institution (hypothetically, those who were not considered mentally ill would be transferred to a more secure facility) and also to receive five dollars for participating. Those who appeared mentally ill would receive an additional five dollars. The honest group received instructions to respond honestly on all measures and each were paid five dollars for participation. All participants completed The Structured Interview of Reported Symptoms (SIRS; Rogers, Bagby, \& Dickens, 1992) and the M-Test (Beaber, Marston, Michelli, $\&$ Mills, 1985); two self-report measures of malingered mental illness. Successful malingering was defined as avoiding elevations on at least six of the eight SIRS subscales. PCL-R scores determined psychopathy classification.

Results indicated that psychopathic individuals were no better than nonpsychopathic individuals at malingering general mental illness on the SIRS and the M-Test. However, results revealed that $90 \%$ of the simulators were confident, measured by self-report, that they avoided detection of malingering on the SIRS. In actuality, only $34 \%$ had not been detected as malingering. Although not significant, a trend was detected that the "good" malingerers were more likely to be psychopathic (74\%) than nonpsychopathic. A criticism of this study is that 
participants were not instructed which psychological disorder to fake; reportedly, most chose to present with psychosis or paranoia. Additionally, participants were defined as lacking severe mental illness based on admission criteria of the facility; it is not clear how this was measured or defined. Thus, results of this study are limited in that they may not generalize to psychological disorders other than psychosis. Also, it is unknown if the participants had any histories of severe mental illness. The study is unpublished, yielding its results to be interpreted with caution. Finally, the generalizability of these results to a community psychopathic population is questionable, since all individuals were incarcerated.

In 2000, Edens, Buffington, and Tomicic reviewed the sparse literature on psychopathy and malingering. The authors concluded that research does not support the assumption that psychopaths are good feigners. One possible explanation for this finding is the context of where the research is conducted. That is, institutional settings increase the likelihood of malingering regardless of one's psychopathology. Another explanation offered is unreliable diagnoses and/or assessments used for the identification of psychopaths. Some measures used in this research such as the Minnesota Multiphasic Personality Inventory (MMPI-2; Hathaway \& McKinley, 1983) Scale 4 (Psychopathic Deviant), do not correlate well with the "gold standard" of measuring psychopathy, the PCL-R.

To clarify these methodological issues, the authors (Edens, Buffington, \& Tomicic, 2000) utilized a repeated measures design to examine the ability of the Psychopathic Personality Inventory (PPI; Lilienfeld \& Andrews, 1996) to detect malingered psychosis by 143 undergraduates (98 females, 45 males). Unlike the PCL-R, the PPI is a brief, self-report measure of psychopathic characteristics (please see Measures below for a detailed description). Participants were instructed to complete the PPI under two conditions: once honestly and once 
while attempting to malinger psychosis. During the malingering condition, participants completed the MMPI Psy-5 Psychoticism Scale (Harkness, McNulty, \& Ben-Proath, 1995). This 25-item self-report tool assessed participants' perceptions of reality and presence or absence of psychotic symptoms. Participants were presented with a hypothetical scenario stating they were arrested for a crime and asked to fake psychosis on the Psy-5 scale to avoid prosecution. They were told to respond in a believable manner because the tests detected exaggeration. Participants received written instructions plus examples of psychotic symptoms (e.g., "hearing or seeing things that other people do not experience (i.e., auditory and visual hallucinations). This information was available for reference throughout the entire study.

Individuals high in psychopathic characteristics were not better at "beating the test" (i.e., malingering psychosis), nor did they perceive themselves to be more successful at malingering psychosis. Malingering was considered present when scores on the PPI Deviant Responding (DR) subscale were 17 or greater and when Psy-5 T scores were not elevated (less than 65). However, by self-report, psychopathic as compared to nonpsychopathic individuals indicated that they were more likely to have a general willingness to malinger mental illness in the future, if involved in a legal scenario. These data demonstrate that the PPI, especially the DR scale, demonstrates good sensitivity (96.3\%) and specificity $(97.6 \%)$ for the detection of malingered psychosis. That is, during the malingering condition all participants produced elevated PPI scores. A known clinical comparison group of people with genuine psychosis was not included. It is not clear if extremely elevated scores on the Psy-5 were considered in determining malingering. Therefore, the classification of malingering was not methodologically sound because validated measures of malingering were excluded. It is unclear if these results would generalize to clinical settings. 
A similar study by Poythress, Edens, and Watkins (2001) was conducted using 55 male inmates divided into two groups. The first group $(n=26)$ received mental illness diagnoses based on previous intake evaluations conducted by mental health staff. These participants were also considered to be mental illness malingerers determined by retrospective judgments of staff psychiatrists. This group was instructed to malinger. The second group $(n=29)$ was classified as free of mental illness and free of malingering based on opinions of mental health staff. This group was instructed to respond honestly. All participants were paid five dollars and additionally, the most successful participant of the malingering group was paid an extra fifty dollars.

Three measures assessed malingering. The Structured Interview of Malingered Symptoms (SIMS; Smith \& Burger, 1997) is a 75-item structured interview (all items rated true or false). Scores above 14 indicate malingering. On the second measure, the SIRS, malingering is present with total scores above 76 , one or more scales elevated to the "definite malingering range," or three or more scale scores greater than or equal to the "probable malingering range." The Personality Assessment Inventory (PAI, Morey, 1991) is a 344-item self report tool used to assess for psychopathology. It is comprised of eleven clinical scales, four validity scales, five treatment scales and two interpersonal style scales. Malingering is indicated on the PAI using three empirically based measurements: PAI Negative Impression Management score greater than or equal to 92; Rogers' discriminant function (RDF; Rogers, Sewell, Morey, \& Ustad, 1996) weighted totals of 20 PAI scale score greater than or equal to 70; and PAI Malingering Index score (Morey, 1996) greater than or equal to five. Presenting as mentally ill on the SIMS, SIRS, and PAI without being detected on the validity scales determined successful malingering.

Results revealed no differences between psychopaths and nonpsychopaths (classified by 
PPI scores) regarding the ability to successfully malinger mental illness on the SIMS, SIRS, and PAI. A criticism is that prison staff psychiatrists used clinical judgments based solely on previous interactions with the participants to classify malingerers. The failure to systematically define malingerers limits the utility of these findings, in addition to the sample being incarcerated, potentially yielding a skewed distribution.

A few studies provide some empirical evidence to suggest that psychopathic individuals may be more convincing malingerers. Gacono, Meloy, Sheppard, Speth, \& Roske (1995) used 36 hospital participants found not guilty by reason of insanity (NGRI). Staff psychiatrists classified half of the participants as malingerers of mental illness based on lack of Axis I psychotic diagnosis by history and staff judgments, lack of psychotropic medication prescriptions, and history of self-reporting of mental illness to receive admission to the hospital. The remaining eighteen participants were considered nonmalingerers. PCL-R scores categorized participants as psychopaths or nonpsychopaths. All malingerers were psychopaths, whereas only two nonmalingerers met criteria for psychopathy. Because of the small number of participants used, results indicated a correlation between psychopathy and malingering. A major methodological flaw is the classification of malingerers and nonmalingerers. Participants were classified based on their self-report of previously faking a mental illness and retrospective clinical judgments. Relying solely on self-report for classification of any psychological construct, especially malingering, is problematic. It is unclear how the nonmalingerers were classified. Finally, the use of an adjudicated sample questions the generalizability of the findings.

In a separate preliminary study, Gacono, Meloy, Speth \& Roske (1997) examined patient files of 18 escapees from a maximum security forensic hospital. PCL-R scores classified escapees as psychopaths and nonpsychopaths. Escapees were likely to be psychopaths and 
classified as malingerers. In this study, no formal assessment of malingering was used. It is unclear how the authors classified malingerers. Furthermore, the authors did not specify the number of escapees who met criteria for psychopathy. All participants were involved with the legal system. Due to these issues, results of this study should be interpreted with caution.

Rogers, Salekin, Sewell, Goldstein, and Leonard (1998) merged data from three psychopathy studies (all defined by the PCL-SV) to determine how often deception occurs in offender populations. The authors conducted a factor analysis on 17 deception criteria found by the authors to be present in all three studies. A factor loading cut-off of .40 formed a three-factor model of deception. These three factors are: implausible presentation (superficial affect and verbal presentation), denial of criminality (detachment from criminal responsibility and blame externalization), and conning and manipulation (deception for personal gains and no regard for others). Implausible presentation represents problematic interpersonal styles. Denial of criminality corresponds with antisocial behavior. Conning and manipulation is associated with Type I psychopathy.

Participants were 120 adolescent male inmates, 150 mentally ill forensic hospital patients, and 103 female inmates. Overall, the 115 individuals who met criteria for psychopathy (PCL-SV scores of 18 or higher) displayed approximately three times the amount of each of the three deception factors listed above as compared to nonpsychopaths. Implausible presentation was revealed in $97.6 \%$ of all psychopaths, as opposed to $27.0 \%$ of nonpsychopaths. Denial of criminality was present in $83.0 \%$ of psychopaths and only $34.9 \%$ of nonpsychopaths. The majority of psychopaths (77.8\%) exhibited conning and manipulation, whereas only $22.4 \%$ of nonpsychopaths demonstrated this. Overall, these data suggest that deception is more represented in psychopathic versus nonpsychopathic offenders. It is unclear if psychopathic offenders were 
able to successfully deceive (i.e., more likely to avoid detection).

In an unpublished study, Billings (2004) examined 60 undergraduate participants for psychopathic characteristics and deception abilities. The researchers classified participants as psychopathic or nonpsychopathic on the PCL-SV and by participants' responses on the short form (56 items) of the PPI. Also, two collateral ratings of psychopathy (provided by classmates, friends or coworkers) were collected for each participant. The author introduced twelve controversial current event topics to each participant (e.g., "Should gay marriages be legalized in the U.S.?"). Each participant indicated if they agreed with each issue. Then each participant received a written speech on four of the twelve topics, preselected by the researcher. Two of the speeches reflected the participant's true opinion (true conditions). The remaining two speeches were against their true opinion (pretend condition).

The author defined deception as convincing naïve undergraduate raters of telling the truth during the pretend condition. Raters ranked each participant's story from 1 to $4(1=$ most truthful, 4 = least truthful). Each participant received ten separate ratings for each of the four speeches. Ratings were averaged yielding a "success at pretense (SAP)" score. The higher the SAP score, the more successful the participant at deceiving. Additionally, trained researchers rated the presence or absence of malingering based on one verbal (speech hesitation) and three nonverbal (illustrators, adaptors, and fidgets) cues. Results indicated that psychopaths were more successful deceivers than nonpsychopaths during speeches as judged by naïve raters on SAP scores. On a self-report measure of confidence, a significant relation among confidence levels, psychopathy, and ability to deceive was not detected. This study examined deception, not malingering. However, these data indicate that psychopathic individuals have a better ability to 
deceive others than nonpsychopaths. Since this study is unpublished and therefore not subjected to peer review, results should be interpreted with caution.

In summary, many of these studies are flawed in the assessment and classification of psychopathy and malingering. For instance, clinical judgments instead of validated measures were used. Regarding deception, results from Billings (2004) and Rogers, Salekin, Sewell, Goldstein, and Leonard (1998) suggest that psychopathic individuals are better deceivers than nonpsychopaths. Inconclusive empirical evidence exists for the relationship between psychopathy and malingering. Clearly, research strategies for examining the malingering and psychopathy relation are in need of refinement. One strategy involves the use of posttraumatic stress disorder, or PTSD, as it is commonly malingered in forensic populations.

\section{Malingering and PTSD}

Research examining the relation between malingering and posttraumatic stress disorder (PTSD) has exponentially grown in the past two decades (see Guriel and Fremouw (2003) for an excellent review). PTSD has been a focus of malingering research due to its prevalence in the general population, its ease to feign as a result of it being a subjectively defined disorder, and its potential financial payoff. The prevalence rates for the malingering of PTSD are not established, however estimates provided by clinicians affiliated with plaintiff attorneys and insurance companies have ranged from 1-50\% (Resnick, 1997). In criminal cases, individuals can use malingering to defer legal action, prevent incarceration, or to receive perceived luxuries such as psychotropic medications while imprisoned. Individuals may use malingering of PTSD within the context of civil scenarios to gain finances, form alliances, or to escape home and occupational duties (Ustad \& Rogers, 1996).

\section{Definition of PTSD}


DSM-IV diagnostic criteria. PTSD is classified as an anxiety disorder. According to the $D S M-I V$ (APA, 2000) diagnostic criteria, to have a diagnosis of PTSD, an individual must have experienced a severely distressing event (e.g., serious accident, war, natural disaster), and perceived that event to "involve actual or threatened death or serious injury, or a threat to the physical integrity of self or others" (p. 467). The individual must have reacted with intense fear, helplessness, or horror. Additionally, an individual must reexperience the distressing event (e.g., nightmares or flashbacks) and demonstrate increased arousal (e.g., poor concentration, exaggerated startle response). An individual with PTSD will avoid anything that could remind them of the distressing event (e.g., people or places that are associated with the event). Finally, the individual should not have experienced these reactions prior to the event, the symptoms must be present for at least one month, and the reactions must cause clinically significant impairment in functioning (e.g., school, work, or social functioning). In the United States, an estimated 90\% of all people experience trauma at least once (Hidalgo \& Davidson, 2000). According to the $D S M-I V$-TR, eight percent of adults develop PTSD (APA, 2000). More specifically, most people in the United States are involved in at least one motor vehicle accident (MVA) by the age of thirty. Each year, approximately three million of those individuals seek medical treatment as a result of a serious MVA. It is estimated that the lifetime prevalence rate for developing PTSD a result of a MVA in the United States is 1 to 3\% (Blanchard \& Hickling, 2004).

\section{Purpose}

The present study examined the relation between psychopathic characteristics and the ability to malinger PTSD caused by a MVA. Most (if not all participants) should have had some knowledge about MVAs due to the high rate of MVA occurrence. This allowed the assessment of the natural ability to malinger PTSD from a MVA without including a coaching element in 
this study as seen in many simulation designs. Because of the above-mentioned prevalence rates of PTSD from a MVA, it was possible to recruit a MVA PTSD positive clinical control group for comparison. Finally, because PTSD is often malingered in forensic settings, findings of this study could provide clinical utility.

This study had many methodological differences and improvements compared to existing research of psychopathy and malingering. It clearly categorized individuals into two groups using the Posttraumatic Stress Diagnostic Scale (PDS; Foa, Cashman, Jaycox, \& Perry, 1997) as a screening tool for PTSD caused by MVA. Individuals with no exposure to an MVA or with a mild rating on the PDS were categorized as trauma negative and instructed to malinger PTSD from a MVA. Individuals with moderate to severe ratings on the PDS (due to trauma from a MVA) were considered trauma positive and instructed to be honest on all evaluations regarding PTSD within the study. The PPI: SF was a second screener that assessed for high and low psychopathic characteristics, separating participants into three groups.

The groups used in the study were: high in psychopathic characteristics, trauma negative; low in psychopathic characteristics, trauma negative; and the clinical comparison condition: trauma positive. Stated differently, these three groups were: psychopathic/malingerers (PM); nonpsychopathic/malingerers (NM); and comparisons (C).

This study examined the ability of participants high and low in psychopathic characteristic to malinger PTSD on two types of measures as compared to controls: a self-report assessment, the Detailed Assessment of Posttraumatic Stress (DAPS; Briere, 2001) and two interviews. The interviews were a structured interview, the Structured Interview for PTSD Scale (SIP; Davidson, Smith, \& Kudler, 1989) and a two minute semistructured interview designed for use in this study. Using two methods for the measurement of PTSD provided a thorough 
assessment of symptom presentation and closely resembled clinical evaluations, which often combine interviews with objective measures.

Using methodology presented in Billings (2004) and Edens, Buffington, and Tomicic, (2000), participants completed the confidence rating and future likelihood of lying forms. This allowed measurement of participants' perceived ability to successfully malinger and participants' report of frequency of lying. Using the Administrator Rating of Believability (ARB) form provided insight regarding the raters' perceptions of the participants' ability to present in a believable manner during the interview portion of the study. Including a multimodal assessment of malingering provided a comprehensive evaluation of the relation between psychopathy and malingering. Presenting a civil litigation scenario created an analog situation similar to that of a clinical practice assessment. In addition to extra credit for participation as suggested by Billings (2004), the participants had a large monetary incentive to be the most convincing: $\$ 100$ to the most successful malingerer and $\$ 100$ to the most convincing presenter from the comparison group.

It has been argued that undergraduate samples are not representative of clinical psychopathic populations. However, research has detected psychopathic characteristics in undergraduates. For example, Salekin, Trobst, and Krioukova (2001) concluded that psychopathy exists within university students and it is more prevalent than expected. In their sample of 326 participants, one out of every 10 males and one out of every 100 females met criteria for psychopathy, assessed with three self-report psychopathy scales. One measure was the ANT scale of the PAI (T score greater than 82). Psychopathy was also determined by positively keyed items on the Self-Report Psychopathy Scale (Hare, 1990). Finally, PPI scores were proportioned with PCL-R scores to warrant psychopathy classifications. 
Research has demonstrated that psychopathic individuals are predominately male (Salekin, Trobst, and Krioukova, 2001). Furthermore, Lilienfeld and Hess (2001) found that males scored significantly higher on all self-report measures of psychopathy than females. Based on the information stated above and on existing psychopathy literature, participants in the current study consisted only of males.

Five hypotheses guided the current study.

1. It was hypothesized that the psychopathic/malingerers group (PM) would score higher on the SIP than participants in the nonpsychopathic/malingerers (NM) and comparison (C) groups. That is, due to interpersonal traits of manipulativeness and deceitfulness, individuals high in psychopathy (PM) would present as more convincing and believable on administrators' ratings on the SIP as compared to individuals low in psychopathic characteristics (NM) and the comparison group (C).

2. It was hypothesized that the psychopathic/malingerers group (PM) would score higher on the Administrator Rating Believability (ARB) than the nonpsychopathic/malingerers (NM) and comparison (C) groups. That is, due to interpersonal traits of manipulativeness and deceitfulness, individuals high in psychopathy (PM) would present as more convincing and believable on administrators' ratings on the ARB as compared to individuals low in psychopathic characteristics (NM) and the comparison group (C).

3. It was hypothesized that the malingering groups (PM and NM) would produce invalid PTSD profiles on the DAPS and the comparison group (C) would endorse valid PTSD profiles. It was expected that the validity scales on the DAPS would detect malingering; individuals in the PM and NM groups would not meet criteria for PTSD and therefore would have no basis to perform better on the measure. 
4. It was hypothesized that the psychopathic malingerers group (PM) would have higher confidence ratings (i.e., would be more confident regarding their ability to convince the raters of truly presenting with PTSD) than individuals in the nonpsychopathic/malingering (NM) and the comparison (C) groups. This assumption was based on previous findings (Kropp, 1992).

5. It was hypothesized the psychopathic/malingerers (PM ) would be more likely to endorse lying in the future than nonpsychopathic/malingerers (NM) and comparisons (C). This was predicted based on previous findings (Edens, Buffington, \& Tomicic, 2000).

\section{Method}

\section{Participants}

Participants initially consisted of 92 male students recruited from undergraduate psychology courses, flyers and sign-up sheets (Appendix A) posted on campus at West Virginia University. Eleven participants were excluded due to age (younger than 18 years) $(n=1)$, revealed condition during Phase Two $(n=2)$, failure to complete both phases of the study $(n=$ $6)$, and procedural errors $(n=2)$. Using upper and lower third cutoffs with the remaining 73 participants in the psychopathic/malingerers (PM) condition on the psychopathy screener (PPI: SF), 25 participants were excluded. The final sample included 56 participants with an average age of 19.9 years. The majority of participants were Caucasian $(78.6 \%)$ reflecting the population of the university. Each malingering group (PM and NM) contained 24 participants and the clinical comparison group contained 8 participants. Average age in years for each group were: PM (19.8), NM (20.2) and C (19.1). A summary of participants' demographic information is provided in Table 4. Statistical analyses revealed no significant group differences on demographic information with the exception of legal conflicts, $F(2,55)=3.312, p<.05$, with strength of effect, as measured by eta squared, of .111. Post hoc analyses (Tukey honestly 
significant different test (HSD) ) indicated that the PM group $(M=.42, S D=.50)$ reported significantly more legal conflicts than the $\mathrm{NM}(M=.13, S D=.34)$ and $\mathrm{C}(M=.13, S D=.35)$ groups. All participants received extra credit for undergraduate psychology courses and two participants (one from the malingering group and one from the comparison group) each received $\$ 100$ based on their success in the study.

Measures (see Appendices B and C)

Posttraumatic Stress Diagnostic Scale (PDS). This 49-item self-report measure was developed by Foa, Cashman, Jaycox \& Perry (1997) for use with 18 to 65-year-olds to determine a presence of a DSM-IV (APA, 1994) PTSD diagnosis. The PDS was revised from an original self-report measure of PTSD (the PTSD Symptom Scale) (Foa, Riggs, Dancu, \& Rothbaum, 1993). Respondents must have an eighth grade reading level to use the PDS. Completion time is 10-15 minutes. The PDS consists of four sections. Part A requires the individual to endorse all traumatic events encountered in their life. Part B identifies the most impacting event and solicits a detailed description of that event. Part C taps into the 17 DSM-IV (APA, 1994) symptoms of PTSD (i.e., reexperiencing, avoidance, and arousal). Each item is rated on a four-point scale $(0=$ not at all or only one time; $3=$ five or more times a week/almost always $)$ yielding a possible range of the symptom severity score of $0-51$. Part D assesses the level of impact of the PTSD symptoms on daily life activities during the previous 30 days.

For PTSD classification on the PDS, an individual must have experienced: 1) a traumatic event that resulted in physical harm or a perceived threat; 2) horror or fear from that event; 3 ) one or more symptoms of reexperiencing; 4) three symptoms of avoidance; 5) two symptoms of arousal; 6) symptoms lasting at least one month; and 7) impairment in daily functioning. Finally, 
the PDS yields a total symptom severity score and three separate symptom scores (i.e., reexperiencing, avoidance, arousal) (Foa et al., 1997).

In a psychometric validation study of the PDS using 248 participants, Foa et al. (1997) reported good internal consistency ( $\alpha=.92$ (total symptom severity), .78 (reexperiencing), .84 (avoidance), and .84 (arousal)). Test-retest reliability using a PTSD diagnosis with 110 of the total participants was demonstrated to be sufficient $(\mathrm{kappa}=.74)$. Test-retest reliability was found to be .83 for total symptom severity, .77 for reexperiencing, .81 for avoidance, and .85 for arousal.

Foa et al. (1997), using the same 248 participants, demonstrated convergent validity of the PDS using the Structured Clinical Interview for the DSM-III-R (SCID; Spitzer, Williams, Gibbons \& First, 1990) and the PDS total symptom severity score to compare PTSD diagnoses; kappa was .65. Furthermore, the PDS sensitivity was .89 and specificity was .75.

Psychopathic Personality Inventory: Short Form (PPI: SF). The original Psychopathic Personality Inventory was developed by Lilienfeld and Andrews (1996). It is a 187-item selfreport scale that examines psychopathic personality traits in community populations. The Psychopathic Personality Inventory utilizes a Likert scale format. Responses range from "False" to "True" rated on a four-point scale. The range for the PPI total score is 187-748.

Administration time of the PPI is approximately 40-60 minutes. Three validity scales are included in the PPI: Positive Impression Management, Deviant Responding, and Consistent Responding. The Psychopathic Personality Inventory consists of eight subscales of psychopathy. They are: Machiavellian Egocentricity (30 items), Social Potency (24 items), Cold-heartedness (21 items), Carefree Nonplanfulness (20 items), Fearlessness (19 items), Blame Externalization (18 items), Impulsive Nonconformity (17 items), and Stress Immunity (11 items). 
The PPI is psychometrically sound and has been tested within a variety of community and forensic populations. Lilienfeld and Andrews (1996) examined the psychometric characteristics of the measure using three samples of undergraduates ( $N=241$ males; 253 males; 610 males and females). Internal consistency of PPI total scores and the eight subscale scores ranged from .90-.93 and .70-.90, respectively. Test-retest reliability (26 day interval) for 57 participants was .95 for the PPI total score and .82-.94 for the eight subscales.

With the same 57 plus 12 additional participants, convergent and discriminant validity was established using other self-report measures. Three measures of psychopathy were correlated with the PPI to determine convergent validity: The California Psychological Inventory Socialization scale (CPI So; Gough, 1960), which measures of the internalization of societal values and delinquency $(r=-.59)$; The Self-Report Psychopathy Scale Revised (SRP-R; Hare, 1985) $(r=.91)$; and the Psychopathy Scale (Levenson, 1990) $(r=.37)$. Furthermore, discriminant validity was established by comparing the PPI to the Perceptual Aberration Scale (PAS; Chapman, Chapman \& Raulin, 1976), which measures sensory perceptions of individuals with psychosis $(r=.07)$; and the General Behavior Inventory (GBI; Depue et al., 1981), which assesses for depression $(r=.22)$, hypomania $(r=.58)$ and cyclothymia $(r=.21)$. (Lilienfeld \& Andrews, 1996).

The PPI has demonstrated sufficient reliability with the PCL-R, the "gold-standard" for the definition and assessment of psychopathy. In a forensic sample of 50 incarcerated males aged 17-21, total PPI score correlated significantly with Factor 1, Factor 2, and the total score of the PCL-R ( $r=.40, .54$, and .54, respectively) (Poythress, Edens, \& Lilienfeld, 1998). The authors also compared PPI total scores to PCL-R total scores (30 or higher classified as psychopathic) to 
demonstrated sensitivity (.50) and specificity (.95) in the classification of psychopathy, correctly identifying $86 \%$ of psychopaths.

A shorter, 56-item version of the PPI was used in the present study. The PPI: SF includes the same eight subscales, each consisting of the seven items with the highest loadings. The short version has been shown to correlate highly $(r=.90$ and above) with the long form of the PPI (Lilienfeld \& Hess, 2001). Additionally, Billings (2004) demonstrated a correlation of .57 between the PPI: SF total score and PCL: SV total score, similar to the correlation between the PPI long version and the PCL-R total scores $(r=.54)$. The range for total score of the short form is $56-224$.

Demographic Questionnaire. A basic demographic questionnaire designed for use in this study examined potential group differences among participants including age, race, year in school, grade point average, marital status, religious affiliation, and history of legal conflicts.

Detailed Assessment of Posttraumatic Stress (DAPS). Developed by Briere (2001), the DAPS assesses the presence of PTSD in males and females 18 years and above (with at least a sixth-grade reading level) who have experienced a traumatic event. The DAPS contains 104 items rated on a five-point scale. Respondents rate each item on its presence in the past month. Completion time is $20-30$ minutes. Items on the DAPS correspond with the 17 DSM-IV (APA, 1994) symptoms of PTSD, including reexperiencing, avoidance, and arousal.

Included in the DAPS are two validity scales (Positive Bias (range 1-40) and Negative Bias (range 1-40)) to detect deviant responses. Additionally the DAPS has four trauma-specific scales (Relative Trauma Exposure (range 0-12), Onset of Exposure (range 1-5), Peritraumatic Distress (range 8-40), and Peritraumatic Dissociation (range 6-30)) and five posttraumatic stress scales (Reexperiencing (range 10-50), Avoidance (range 10-50), Hyperarousal (range 10-50), 
Posttraumatic-Stress Total (range 30-150), and Posttraumatic Impairment (range 5-25)). A unique feature of the DAPS are three additional scales: Trauma-Specific Dissociation (range 120), Suicidality (range 10-50), and Substance Abuse (range 10-50); these scales provide insight into residual effects of the trauma. The DAPS yields a presence or absence of a PTSD diagnosis. Briere (2001) used a normative sample of over 400 individuals from clinical, community, and college participants for development of the DAPS. Each participant had experienced one or more significant trauma in their lives. Acceptable reliability and validity was established in the normative sample with an average internal consistency for the clinical scales of .83; and, .71 and .52 for the two validity scales. Significant interscale correlations ranged from .09-.94. Using various validated measures of PTSD, convergent validity was established. The Positive Bias Scale of the DAPS related positively with other "faking good" scales within the Trauma Symptom Inventory (TSI; Briere, 1995), PAI, and MMPI-2 (correlations ranging from .33-.49) and negatively with other "faking bad" scale within the TSI, PAI, and MMPI-2 (correlations ranging from -.31 to -.42). The Negative Bias Scale of the DAPS correlated positively with the "faking bad" scales listed above, correlations ranging from .53 to .58 , and negatively with the "faking good" scales listed above, correlations ranging from -.09 to -.43) (Briere, 2001). Convergent validity was also demonstrated with the three DAPS PTSD symptoms scales (Reexperiencing, Avoidance and Arousal) and symptoms scales within the Impact of Events Scale (IES; Horowitz, Wilner, \& Alvarez, 1979), the Clinician Administered PTSD Scale (CAPS: Blake et al., 1990, 1995), the PTSD Checklist (PCL; Weathers, Litz, Herman, Huska, \& Keane, 1993), the Civilian Mississippi Scale (Vreven, Gudanowski, King, \& King, 1995), the TSI, PDS, and PAI (correlations ranging from .53-.89) (Briere, 2001). 
Discriminant validity of the DAPS was established with the three symptom scales of the DAPS and four scales of the PAI (Depression, Somatization, Antisocial, and Mania), correlations ranging from -.01 to -.78 (Briere, 2001). Comparing the DAPS PTSD diagnoses with the CAPS PTSD diagnoses on 69 participants yielded good sensitivity (.88) and specificity (.86).

The Structured Interview for PTSD Scale (SIP; Davidson, Smith, \& Kudler, 1989; Davidson, Malik, \& Travers, 1997). The SIP was initially developed in 1989 to assess the symptom presentation of DSM-III-R (APA, 1987) PTSD criteria. The SIP was updated to match the DSM-IV (APA, 1994) revisions and requires 10-30 minutes of administration time. On this measure, 17 items are rated on a five-point Likert scale with responses ranging from 0 (none) to 4 (extremely severe). The possible range for this measure is 0-68. Each item is assessed on three dimensions: frequency, severity, and level of impairment to determine if an individual meets PTSD diagnostic criteria. Included in the SIP are two ratings of guilt as a result of the traumatic event. The SIP also provides a symptom severity score.

In a validation study for the revised SIP using 68 participants with PTSD diagnoses, Davidson et al. (1997) indicated the instrument to have good reliability $(\alpha=.80)$; test-retest reliability for 26 participants resulted in a Pearson correlation coefficient of .89. Interobserver agreement for eight participants was .90. Additionally, the SIP demonstrated acceptable validity. Concurrent validity was determined using the Davidson Trauma Scale (DTS; Davidson, 1996) and the Impact of Events Scale (IES; Horowitz et al., 1979); Pearson correlation coefficients were .67 and .49 respectively. Compared with the SCID, using a score of 20, sensitivity, specificity, positive predictive value, negative predictive value and efficiency of the SIP all were $100 \%$, demonstrating excellent diagnostic utility.

Administrator Rating of Believability Questionnaire (ARB). A questionnaire was 
designed for use in this study to examine the administrators' perceptions of the believability of each participant. Responses range from strongly agree to strongly disagree on a four-point scale with a possible range of 4-16. This questionnaire is based on a similar measure by Billings (2004).

Confidence Questionnaire (CQ). Designed for use in this study, the self-report CQ examined participants' confidence levels regarding successfully avoiding detection of malingering of PTSD in the study. Responses ranged from strongly agree to strongly disagree on a four-point scale with a possible range of 4-16. This questionnaire is based on similar measures used in Billings (2004).

Future Likelihood of Lying Questionnaire (FLL). This self-report measure, developed for use in this study, examined participants' endorsement of future likelihood of lying and frequency of lying. Responses ranged from strongly agree to strongly disagree on a four-point scale with a range of 4-18. This questionnaire is based on a similar measure used in Edens, Buffington, \& Tomicic (2000).

Criteria Checklist. Also developed for use in this study was a criteria checklist, administered upon completion of the study. Participants endorsed the condition to which they were assigned (honest or malingering) as well as provided open-ended responses about what they would have done differently, given the opportunity. Participants also rated the importance of the $\$ 100$ incentive for participation in this study ( $1=$ not at all important to $4=$ very important).

Contact Information Form. This form, developed for use in the study, provided researchers with a means of contacting (email addresses) the two most successful participants to award them each with the monetary prize of $\$ 100$.

\section{Procedure}


The present study occurred in two phases.

Phase One. After providing informed consent (Appendix D), participants completed the PDS screener and were classified into one of two groups based on their responses: MVA trauma positive (comparison) $(n=8)$ and MVA trauma negative (malingerers) $(n=73)$. (Total symptom severity scores in the moderate to severe range (11-51) were considered trauma positive and total symptom severity scores in the no rating to mild (0-10) range were considered trauma negative). All participants then completed the demographic form and the PPI: SF. Phase One lasted approximately 50-60 minutes and occurred in a laboratory in the Life Sciences Building at West Virginia University.

All participants then immediately proceeded to the second phase. Participants with PDS scores in the moderate to moderate to severe range (none scored in the severe range) received instructions to use their true MVA experience during Phase Two. Participants with PDS scores in the no rating to mild range received instructions to malinger a traumatic MVA experience during Phase Two. The Phase One administrator provided each participant with the written instructions immediately prior to entering the second phase. The Phase One administrator explained that the Phase Two administrator would be masked to their condition and if they revealed their assigned condition to the Phase Two administrator, disqualification would result. The Phase One administrator explained that all participants would be presented with the goal of passing the evaluation to earn $\$ 100,000.00$ in a hypothetical civil litigation scenario during Phase Two.

Phase Two. Phase Two consisted of 81 participants. Only the 48 participants with PPI scores in the upper and lower third range were analyzed. Eight participants were in the clinical comparison group. Therefore, the three final groups in this study were: psychopathic 
malingerers: PM $(n=24)$, nonpsychopathic malingerers: $\mathrm{NM}(n=24)$, and comparisons: $\mathrm{C}(n=$ 8).

Participants met with the Phase Two Administrator (the student investigator or a research assistant) in the adjacent room of the Phase One laboratory. All Phase Two administrators were females to control for any gender effects during interviews. All wore business casual attire and were masked to participant condition. None interviewed participants with whom they were acquainted. During Phase Two, if any participant revealed his assigned condition, the administrator terminated the interview.

Instructions (adapted from a study by Guriel et al., 2004) describing this portion of the study were read to the participant. These instructions provided a hypothetical civil litigation scenario and informed participants that within the hypothetical scenario, they could be awarded $\$ 100,000.00$ for "pain and suffering" if they could successfully convince the forensic psychologist (i.e., the administrator) that they were suffering from PTSD.

The administrator informed the participants that they had two minutes to prepare their scenario and also stated that the top two most convincing participants in this study would win $\$ 100$. Once it was determined that the participant understood the task, the administrator left the room for two minutes. Then, the administrator returned to the room, began tape-recording the session, and instructed the participant to tell his story. The administrator started a timer as soon as the participant began talking. The participant had two minutes to tell his true story/lie. The administrator signaled when one minute remained and finally when 30 seconds remained. Up to four prompts could have been used for each participant (i.e., "Tell me more about what happened.") if necessary. Upon completion of the two minutes, the administrator completed the 
first two items on the rater believability measure. Then the administrator conducted the 10-30 minute SIP interview, and finally completed the last two items on the rater believability measure.

Next, the participant returned to the Phase One room and the Phase One administrator gave the participant the DAPS, informing him to complete it as if in the hypothetical scenario. Upon completion, the participant honestly completed (disregarding the hypothetical scenario) the three self-report questionnaires to rate his level of confidence, future likelihood of lying and a criteria check. Additionally, the participant recorded his email address on an information sheet. This contact information was only used if the participant was ranked one of the two most convincing. Phase Two lasted approximately 55-70 minutes. Upon completion of the study, participants were debriefed (Appendix E).

Reliability. Three independent researchers performed reliability checks on twenty-five percent of the SIP interview responses and administrator believability forms using videotapes. Reliability was calculated using intraclass correlations. One hundred percent of the data were double checked by research assistants for scoring and computer entry errors.

Monetary rewards. Upon completion of the study, data were examined for each participant that completed the entire study. The most successful participant in each of the two groups (malingerers and comparisons) received the $\$ 100$ prize. Successfulness was determined by: (a) valid and clinically significant elevations on DAPS profiles (based on PB scores less than 7 (T score less than 65), NB scores less than 12 ( $T$ score less than 75), PTSD impairment scores greater than 11 (T scores greater than 65), PTSD stress scores greater than 58 (T scores greater than 65) and presence of PTSD diagnosis), (b) and highest administrator ratings of SIP scores and a PTSD diagnosis on the SIP, and (c) highest administrator believability ratings. 


\section{Preliminary Analyses}

Participants were screened for presence of PTSD due to a motor vehicle accident based on PDS symptom severity ratings. Scores of 0 to 10 identified participants as trauma negative. PDS scores of eleven or higher classified participants as trauma positive. A one-way analysis of variance (ANOVA) comparing group means on PDS symptom severity score demonstrated a significant effect among groups $F(2,55)=20.592, p<.001$, with strength of effect, as measured by eta squared, of .437 . Tukey HSD post hoc analyses indicated that the C group $(M=22.50, S D$ =4.11) had PDS symptom severity scores significantly higher than the two malingering groups (PM: $M=5.58, S D=6.74, \mathrm{NM}: M=4.38, S D=8.26$ ). For the comparison group, all participants met criteria for PTSD from a MVA, with symptom severity scores of 16-29 (moderate and moderate to severe). Three participants scored in the moderate range (11-20) and five scored in the moderate to severe range (21-35). No participants in the malingering groups met criteria for PTSD from a MVA. For the PM group, 20 of 24 participants reported exposure to the following traumas: MVA $(n=12)$, nonsexual assault by a known person $(n=3)$, natural disaster $(n=2)$, nonsexual assault by a stranger $(n=1)$, imprisonment $(n=1)$, and lifethreatening illness $(\mathrm{n}=1)$. Three participants received moderate $(11-20)$ and one received moderate to severe (21-35) symptom severity ratings of PTSD due to a trauma other than a MVA. For the NM group, 21 of 24 participants reported exposure to a traumatic event: MVA ( $n$ $=12$ ), other accident $(n=1)$, natural disaster $(n=1)$, nonsexual assault by a stranger $(n=1)$, nonsexual assault by a known person $(n=1)$, imprisonment $(n=1)$, and other $(n=4)$. One participant received moderate (11-20) and two received moderate to severe (21-35) symptom severity ratings of PTSD due to a trauma other than a MVA. 
The PPI was used as a second criterion measure to classify participants in the malingering group as either high or low in psychopathic characteristics based on upper and lower tertiary cutoffs. An ANOVA compared mean differences of PPI total scores among all three groups. A significant effect was revealed, $F(2,55)=83.473, p<.001$, with strength of effect measured by eta squared, .759. Tukey HSD post hoc analyses indicated that the PM group $(M=146.42, S D=$ 7.16) had significantly higher scores on the PPI than the C $(M=127.00, S D=9.78)$ and NM $(M$ $=119.17, S D=6.77$ ) groups, and the C group had significantly higher PPI scores than the NM group.

Prior to testing hypotheses, three trained research assistants independently rated videotapes of SIP and ARB interviews from Phase Two to ensure reliable scoring on both measures. Analyses were performed on $21(37.5 \%)$ of the 81 total interviews, yielding intraclass correlations of .9201 (single measure) and .9787 (average measure) on SIP total scores. Both were significant $(p<.0001)$. The inter-rater reliability alpha coefficient for the same 21 interviews on the SIP was .9811 . Using the same research assistants rating the same 21 interviews, intraclass correlations on ARB total scores were .2868 (single measure) and .6166 (average measure) on ARB total scores. Both were significant $(p<.01)$. The inter-rater reliability alpha coefficient for the same 21 interviews on the ARB was .6249.

\section{Primary Analyses}

Table 5 provides summaries of total scores on the SIP and ARB interviews from Phase Two. An ANOVA was conducted to examine group differences on SIP total score. No significant differences were detected among groups $F(2,55)=1.610$. Additionally, an ANOVA was performed to examine group differences on ARB total score. Again, no significant group differences were present, $F(2,55)=0.007$. This indicates that participants high in psychopathic 
characteristics did not present with higher levels of PTSD based on raters' judgments as compared to the low in psychopathic characteristics and comparison groups. Furthermore, contrary to predictions stated in the first and second hypotheses, individuals high in psychopathic characteristics were no better at convincing raters of psychological problems due to PTSD than individuals low in psychopathic characteristics or trauma positive individuals ${ }^{12}$.

To test the third hypothesis, four separate ANOVAs were conducted to examine group differences on four DAPS subscales (Positive Bias (PB), Negative Bias (NB), Posttraumatic Stress total (ST), and Posttraumatic Impairment (IMP) total). No significant differences were detected among groups on the NB, ST, and IMP subscales. However, on the PB validity scale there were significant differences among groups, $F(2,55)=3.963, p<.05$, with strength of effect as measured by eta squared as .130. Subsequent Tukey HSD post hoc tests were performed to determine where group differences existed. Results indicated that the NM group was significantly different from the C group on the PB scale of the DAPS (see Table 6 for means, standard deviations, and $F$ values). That is, the NM group had significantly higher "faking good" scores on the DAPS PB scale as compared to the C group. These findings are contrary to hypothesis three since both the malingering and comparison participants produced similar profiles on the DAPS. The comparison group was no better than the malingering group at avoiding detection of malingering on this measure ${ }^{12}$.

As mentioned previously, success on the DAPS was determined by producing valid and elevated profiles based on the following five criteria: PB scores less than 7, NB scores less than 12, PTSD impairment scores greater than 11, PTSD stress scores greater than 58 and presence of PTSD diagnosis. There were no significant group differences on the percent of valid and

\footnotetext{
${ }^{1}$ Statistical analyses were also conducted using median splits on the PPI, revealing similar results.

${ }^{2}$ Due to unequal group sizes, nonparametric statistical analyses were conducted, revealing similar results.
} 
elevated DAPS profiles $\left(X^{2}=.693, \mathrm{df}=2\right)$. However, a noteworthy finding is that 9 of the 56 participants produced valid and elevated DAPS profiles, thus avoiding detection of malingering, while pretending to be in the hypothetical civil litigation scenario (see Table 7).

Total scores on the Confidence Questionnaire (CQ) are summarized in Table 8. An ANOVA was conducted to examine group differences on CQ total scores. No significant group differences were detected $F(2,55)=.439$, despite predictions from hypothesis four. That is, there were no differences among participants on levels of confidence by self-report. Individuals high in psychopathic characteristics were not more likely to report higher levels of confidence in successfully avoiding detection of malingering PTSD. ${ }^{3}$

Total scores on the Future Likelihood of Lying Questionnaire (FLL) are also summarized in Table 8. An ANOVA was conducted to examine group differences on the FLL total scores. Significant group differences were revealed, $F(2,55)=4.228, p<.025$, with strength of effect measured by eta squared as .138. Tukey HSD post hoc analyses indicated that the NM group reported a significantly higher likelihood of lying in the future than the PM group. These results are the exact opposite than those predicted in hypothesis five. ${ }^{34}$

\section{Discussion}

Contrary to expectations, participants high in psychopathic characteristics were not more successful in avoiding detection of malingering PTSD compared to participants low in psychopathic characteristics on interviewer ratings. Furthermore, individuals high in psychopathic characteristics were not more confident about their success, nor were they more likely to report a greater propensity for lying. As predicted, participants high in psychopathic characteristics were not better at avoiding detection of malingering on the DAPS than

\footnotetext{
${ }^{3}$ Statistical analyses were also conducted using median splits on the PPI, revealing similar results.

${ }^{4}$ Due to unequal group sizes, nonparametric statistical analyses were conducted, revealing similar results
} 
participants low in psychopathic characteristics. Overall, results from this study failed to demonstrate that individuals high in psychopathic characteristics are more successful malingerers on interview or self-report measures.

\section{Psychopathy and Malingering on Administrator Ratings}

Psychopathy is a construct that includes manipulative, deceitful traits (Cleckley, 1988).

Based on this definition, it was hypothesized that individuals high in psychopathic characteristics would be rated higher on the administrator ratings (SIP and ARB) compared to individuals low in psychopathic characteristics and comparisons. It was expected that individuals high in psychopathic characteristics would utilize interpersonal skills of deception to present in a more believable manner during the open-ended assessment and structured interview, thus avoiding detection of malingering. Results indicated no significant group differences of this success rate on the SIP and ARB interviews.

Results from this study are inconsistent with those presented by Billings (2004) which demonstrated that psychopathic individuals were more effective than nonpsychopaths at deceiving naïve raters while giving a speech. Deception was defined as successfully convincing raters of being sincere during pretend conditions. Although Billings examined deception, whereas the present study examined malingering, similar results were expected based on the use of administrator interviews.

It is possible that the sample in the present study had lower PPI scores than the sample in Billings. However, Billings reported the means and standard deviation for his 60 undergraduates as 128.80 (12.10) with a range of 99-152. Using all 81 participants, the PPI mean, standard deviation, and range in the present study were slightly higher: 132.14 (12.47), 100-167. Therefore, PPI: SF results from both studies are comparable and the samples did not differ. 
One explanation for the inconsistent results between studies is the difference in naïve versus trained raters. Billings recruited college students to rate deceivers whereas the present study utilized trained research assistants to rate participants. Billings' naïve raters accurately detected deception in $57 \%$ of speeches, which is a hit rate just above chance. This indicates that naïve raters are not sophisticated in the detection of deception. Finally, the Billings study is recent and unpublished and therefore results have not been replicated.

\section{Psychopathy and Malingering on the Self-Report Measure}

It was assumed that participants in the malingering condition would not avoid detection of malingered PTSD. As expected, results from this study indicated that participants were not good at avoiding detection of malingering on this measure. The low in psychopathic characteristics group unexpectedly presented with significantly higher scores on the Positive Bias validity scale of the DAPS, indicating a propensity for participants in this group to present in a more positive light than the high in psychopathic characteristics or comparison groups. A possible explanation of this finding is that individuals high in psychopathic characteristics are more sophisticated than individuals low in psychopathic characteristics in regards to presenting in a believable manner and faking good. Those high in psychopathic characteristics possibly attended more to the salient negative components (e.g., extreme emotional distress, pain and suffering) of the study. If this is true, psychopaths may be better at successful malingering with coaching and practice.

Contrary to expectations, analyses revealed that the majority of the comparison group did not produce valid profiles on the DAPS. It was expected that this group would be more successful at producing valid profiles due to a presence of PTSD and a familiarization with posttraumatic symptoms. It is unlikely that invalid profiles were a result of an absence of true 
extreme traumatic stress symptoms, as none scored in the severe range on the PDS. It is possible that these participants produced invalid profiles because the hypothetical scenario prompted them to exaggerate symptoms. Instructing the clinical comparison group to discuss their true MVA experience in Phase Two without presenting the hypothetical scenario may have yielded the predicted results. Because nine of 58 participants produced valid DAPS profiles while pretending to be in the hypothetical civil litigation scenario, the clinical utility of the DAPS measure for detecting malingering remains questionable until further research is conducted on its psychometric properties, especially regarding the validity scales.

Results from the present study are comparable to Edens, Buffington and Tomicic (2000), indicating that psychopaths are not successful feigners on standardized assessments. Edens et al. presented participants with a hypothetical criminal scenario that instructed participants to feign psychosis in a believable manner to avoid prosecution. The current study presented a civil hypothetical that instructed participants to feign PTSD from a MVA in a believable manner to gain financial compensation. Edens et al. did not include a known comparison group; however, even with the inclusion of a comparison group in the present study, similar results surfaced. Although Edens et al. coached participants (i.e., provided descriptions of psychosis), psychopathic individuals were not better than nonpsychopathic individuals at "beating the test." An explanation is that college students may not be familiar with psychosis.

Due to the high rate of occurrence of PTSD and MVAs in the general population, college students are likely more familiar with the hypothetical in the present study. Hence, a direct coaching component (e.g., providing descriptions of posttraumatic stress symptoms) was not included in the present study. The instructions for the hypothetical scenario did, however, state, "PTSD is the name of a psychological disorder that individuals may develop that is caused by 
exposure to a traumatic event such as a motor vehicle accident. When someone has PTSD they are in extreme emotional distress." It is possible that participants in this study exaggerated extreme emotional distress and as a result presented in a less believable manner. Perhaps providing participants with more direct coaching could yield higher success rates for all participants of avoiding detection of malingered PTSD.

\section{Psychopathy, Confidence, and Lying}

Pathological lying is one trait included in the psychopathic makeup (Cleckley, 1988). Although confidence is not included in the definition, this variable has been associated with psychopathy in recent research (Billings 2004; Kropp 1992). Therefore, it was predicted in this study that participants high in psychopathic characteristics would be more confident of their malingering abilities and more likely to lie. Results from this study did not support the assumption that psychopaths are more confident in their malingering performance, nor the prediction that psychopaths are more likely to endorse a higher frequency of lying.

Kropp (1992) demonstrated that the majority of participants, regardless of psychopathy classification, were more likely to report confidence in successful malingering although just over one third of participants actually were successful. His results are not consistent with the results from this study. One reason for this finding is that he used an institutionalized sample that was “psychologically knowledgeable." In addition, participants were asked to feign a mental illness of their choice. It is possible that because participants in the present study had no control of which disorder to malinger they perceived themselves as less confident. Curiously, the comparison group was not more confident of the believability of their performance; perhaps an explanation for this is that the hypothetical scenario interfered with their true story. Again, adding a comparison group instructed to respond honestly without presenting the hypothetical 
could possibly clarify this issue. Additionally, the present study failed to collect information from participants regarding historical or current presence of psychopathology other than PTSD. Furthermore, information was not collected regarding past or present participation in psychological treatment. It is therefore unknown if participants were "psychologically knowledgeable." If participants were indeed "unknowledgeable," this could have contributed to their lack of confidence.

Results from Billings (2004) and Edens, Buffington, and Tomicic (2000) are comparable to results from the present study regarding confidence ratings for presenting in a believable manner. No significant relation was found between psychopathy classification and level of confidence. This suggests that confidence may not be a feature of psychopathy.

Contrary to predictions, participants high in psychopathic characteristics in this study did not endorse a higher frequency of lying. This finding was unexpected, as a propensity to lie is included in the definition of psychopathy. It is noteworthy that individuals low in psychopathic characteristics did report a higher frequency of lying than the participants high in psychopathic characteristics. These results do not corroborate with results from Edens, Buffington, and Tomicic (2000). This could be explained by the differences in questions; the present study questioned participants about their general frequency of lying whereas Edens et al. questioned participants about their willingness to lie if presented with different forensic situations. Perhaps modifying the questions in the present study to mirror those in the Edens et al. study would produce similar results. Another interpretation of findings from this study is that individuals high in psychopathic characteristics do not lie as frequently as individuals low in psychopathic characteristics. It is also possible that the group high in psychopathic characteristics potentially attended to social desirability and therefore responded dishonestly to this measure. 


\section{Limitations of the Current Study}

Although this study was the first to examine the relation of psychopathic characteristics and malingering using a multimodal assessment, several limitations must be noted. Although PPI means of participants in this study were similar to those in other studies using a college population, findings may not generalize to larger sample of "true psychopaths," as the PPI demonstrates only a .54 correlation with the PCL-R. This raises suspicion about potential differences between college students high in psychopathic traits and institutionalized psychopaths. Although the PPI had validity scales, it is a self-report measure. A collateral measure should be incorporated into the determination of psychopathy; ideally, classification of psychopathy should be validated further with the "gold-standard" PCL-R.

This small college sample is problematic. The sample lacks heterogeneity and therefore questionable generalizability. In addition, the comparison group was small and none of the comparison participants produced scores in the severe range of PTSD symptom severity on the PDS. Including a true clinical comparison group would solve this problem. It would be useful to replicate this study adding a true clinical PTSD group without presenting the hypothetical scenario to determine if the scenario influenced performance on the measures.

Simulation designs are not real world events. It is possible that the hypothetical scenario presented in this study did not produce motivation for the participants to make whole-hearted attempts to malinger PTSD. All participants received extra credit for participation, which provided immediate reinforcement upon completion of the study. However, the extra credit may not have been enough of an incentive for participants to put forth maximum effort in the study. Although participants were aware that two individuals would each receive $\$ 100$, the uncertainty and delay of the monetary reward also could have contributed to performance. This limits the 
generalizability of these findings to realistic civil litigation in which recovery from alleged damages provides a much greater incentive to avoid detection of malingered PTSD (e.g., greater financial rewards, lifetime disability benefits).

Another weakness of this study is the lack of inclusion of a malingering-specific measure such as the SIMS or SIRS. Adding such a measure would validate the ability of the DAPS in detecting malingering.

Results from the present study suggest that individuals high in psychopathic characteristics are not better than individuals low in psychopathic characteristics at avoiding the detection of malingering on interviewer assessments of PTSD. However, before abandoning the assumption that psychopaths are not successful feigners, results from this study should be replicated using an incarcerated psychopathic population classified by PCL-R scores greater than or equal to thirty. 


\section{References}

American Psychiatric Association. (1952). Diagnostic and Statistical Manual of Mental Disorders (1st ed.). Washington, D.C.: Author.

American Psychiatric Association. (1968). Diagnostic and Statistical Manual of Mental Disorders (2nd ed.). Washington, D.C.: Author.

American Psychiatric Association. (1980). Diagnostic and Statistical Manual of Mental Disorders (3rd ed.). Washington, D.C.: Author.

American Psychiatric Association. (1987). Diagnostic and Statistical Mmanual of Mental Disorders (3rd ed.-rev.). Washington D. C.: Author.

American Psychiatric Association. (1994). Diagnostic and Statistical Manual of Mental Disorders (4th ed.). Washington, D.C.: Author.

American Psychiatric Association. (2000). Diagnostic and Statistical Manual of Mental Disorders (4th ed., text revision). Washington, D.C.: Author.

Arrigo, B. A., \& Shipley, S. (2001). The confusion over psychopathy (I): Historical considerations. International Journal of Offender Therapy and Comparative Criminology, 45, 325-344.

Beaber, R. J., Marston, A., Michelli, J., \& Mills, M. J. (1985). A brief test for measuring malingering in schizophrenic individuals. American Journal of Psychiatry, 142, 14781481.

Billings, F. J. (2004). Psychopathy and the ability to deceive. Unpublished doctoral dissertation, University of Texas at El Paso.

Blake, D. D., et al. (1990). A clinician rating scale for assessing current and lifetime PTSD: The CAPS-1. The Behavior Therapist, 13, 187-188. 
Blake, D. D., et al. (1995). The development of a clinician-administered PTSD scale. Journal of Traumatic Stress, 8, 75-90.

Blanchard, E. B., \& Hickling, E. J. (2004). After the crash: Psychological assessment and treatment of survivors of motor vehicle accidents (2nd ed.). Washington, D.C.: American Psychological Association.

Briere, J. (1995). Trauma Symptom Inventory. Odessa, FL: Psychological Assessment Resources. Briere, J. (2001). Detailed Assessment of Posttraumatic Stress (DAPS). Odessa, FL: Psychological Assessment Resources.

Cale, E. M., \& Lilienfeld, S. O. (2003). What every forensic psychologist should know about psychopathic personality. In W. T. O’Donohue \& E. R. Levensky (Eds.), Handbook of forensic psychology: Resource for mental health and legal professionals (pp.395-428). New York: Elsevier Academic Press.

Chapman, L. J., Chapman, L. J., \& Raulin, M L. (1976). Body-image aberration in schizophrenia. Journal of Abnormal Psychology, 87, 374-382.

Cleckley, H. (1988). The mask of sanity (5 ${ }^{\text {th }}$ ed. ). St. Louis: Mosby.

Cunnien, A. J. (1997). Psychiatric and medical syndromes associated with deception. In R. Rogers (Ed.), Clinical assessment of malingering and deception (2nd ed.) (pp. 23-46). New York: The Guilford Press.

Davidson, J. R. T. (1996). Davidson Trauma Scale. Multi-Health Systems, Inc.

Davidson, J. R. T., Smith, R. D., \& Kudler, H. S. (1989). Validity and reliability of the DSM-III criteria for posttraumatic stress disorder. Experience with a structured interview. Journal of Nervous and Mental Disease, 177, 336-341.

Davidson, J. R. T., Malik, M. A., \& Travers, J. (1997). Structured Interview for PTSD (SIP): Psychometric validation for DSM-IV Criteria. Depression and Anxiety, 5, 127-129. 
Depue, R. A., Slater, J. F., Wolfstetter-Kausch, H., Klein, D., Goplerud, E., \& Farr, D. (1981). A behavioral paradigm for identifying persons at risk for bipolar depressive disorder: A conceptual framework and five validation studies. Journal of Abnormal Psychology, 90, $380-437$.

Edens, J. F., Buffington, J. K., \& Tomicic, T. L. (2000). An investigation of the relationship between psychopathic traits and malingering on the psychopathic personality inventory. Assessment, 7, 281-296.

Foa, E. B., Cashman, L., Jaycox, L., \& Perry, K. (1997). The validation of a self-report measure of posttraumatic stress disorder: The Posttraumatic Stress Diagnostic Scale. Psychological Assessment, 9, 445-451.

Foa, E. B., Riggs, D. S., Dancu, C. V., \& Rothbaum, B. O. (1993). Reliability and validity of a brief instrument for assessing post-traumatic stress disorder. Journal of Traumatic Stress, 6, 459-473.

Gacono, C. B., Meloy, J. R., Sheppard, K., Speth, E., \& Roske, A. (1995). A clinical investigation of malingering and psychopathy in hospitalized insanity acquittees. Bulletin of the American Academy of Psychiatry and Law, 23, 387-397.

Gacono, C. B., Meloy, J. R., Speth, E., \& Roske, A. (1997). Above the law: Escapes from a maximum security forensic hospital and psychopathy. Journal of the American Academy of Psychiatry and the Law, 25, 547-550.

Gough, H. G. (1960). Theory and method of socialization. Journal of Consulting and Clinical Psychology, 24, 23-30.

Guriel, J., \& Fremouw, W. (2003). Assessing malingered posttraumatic stress disorder: A critical review. Clinical Psychology Review, 23, 881-904. 
Guriel, J., Yañez, T., Fremouw, W., Shreve-Neiger, A., Ware, L., Filcheck, H., \& Farr, C. (2004). Impact of coaching on malingered posttraumatic stress symptoms on the M-Fast and the TSI. Journal of Forensic Psychology Practice, 4, 37-56.

Hare, R. D. (1980). A research scale for the assessment of psychopathy in criminal populations. Personality and Individual Differences, 1, 111-119.

Hare, R. D. (1985). Comparison of procedures for the assessment of psychopathy. Journal of Consulting and Clinical Psychology, 53, 7-16.

Hare, R. D. (1990). The Self-Report Psychopathy Scale-II. Unpublished test, Department of Psychology, University of British Columbia, Vancouver, Canada.

Hare, R. D. (1991). The Hare Psychopathy Checklist-Revised manual. Toronto, Canada: MultiHealth Systems.

Hare, R. D. (1996). Psychopathy: A clinical construct whose time has come. Criminal Justice Behavior, 23, 25-54.

Harkness, A. R., McNulty, J. L., \& Ben-Porath, Y. S. (1995). The personality psychopathology five (PSY-5): Constructs and MMPI-2 scales. Psychological Assessment, 7, 104-114.

Hart, S. D., Hare, R. D., \& Forth, A. E. (1994). Psychopathy as a risk marker for violence: Development and validation of a screening version of the Revised Psychopathy Checklist. In J. Monahan \& H. J. Steadman (Eds.), Violence and Mental Disorder: Development in Risk Assessment, (pp. 81-98). Chicago: University of Chicago Press. Hathaway, S. R., \& McKinley, J. C. (1983). The Minnesota Multiphasic Personality Inventory manual. New York: The Psychological Corporation.

Hidalgo, R. B., \& Davidson, J. R. (2000). Posttraumatic stress disorder: Epidemology and health-related considerations. Journal of Clinical Psychiatry, 61(Suppl. 7), 5-13. Horowitz, M., Wilner, N., Alvarez, W. (1997). Impact of Event Scale: a measure of subjective 
stress. Psychosomatic Medicine, 41, 209-218.

Kropp, P. R. (1992). The relationship between psychopathy and malingering of mental illness. Unpublished mater's thesis, Simon Frasier University, Burnaby, British Columbia, Canada.

Levenson, M. R. (1990). Risk taking and personality. Journal of Personality and Social Psychology, 58, 1073-1080.

Lilienfeld, S. O., \& Andrews, B. P. (1996). Development and preliminary validation of a selfreport measure of psychopathic personality traits in noncriminal populations. Journal of Personality Assessment, 66, 488-524.

Lilienfeld, S. O., \& Hess, T. H. (2001). Psychopathic personality traits and somatization: Sex differences and the mediating role of negative emotionality. Journal of Psychopathology and Behavioral Assessment, 23, 11-24.

Morey, L. C. (1991). Personality Assessment Inventory: Professional manual. Odessa, FL: Psychological Assessment Resources.

Morey, L. (1996). An interpretive guide to the Personality Assessment Inventory (PAI). Odessa, FL: Psychological Assessment Resources.

Poythress, N. G., Edens, J. F., \& Lilienfeld, S. O. (1998). Criterion-related validity of the Psychopathic Personality Inventory in a prison sample. Psychological Assessment, 10, 426-430.

Poythress, N. G., Edens, J. F., \& Watkins, M. M. (2001). The relationship between psychopathic personality features and malingering symptoms of major mental illness. Law and Human Behavior, 25, 567-582.

Resnick, P. J. (1997). Malingering of posttraumatic disorders. In R. Rogers (Ed.), Clinical assessment of malingering and deception (2nd ed.) (pp. 130-152). New York: The 
Guilford Press.

Rogers, R. (1990a). Development of a new classificatory model of malingering. Bulletin of the American Academy of Psychiatry and the Law, 18, 323-333.

Rogers, R. (1990b). Models of feigned mental illness. Professional Psychology: Research and Practice, 21, 182-188.

Rogers, R. (1997). Introduction. In R. Rogers (Ed.), Clinical assessment of malingering and deception (2nd ed.) (pp. 1-19). New York: The Guilford Press.

Rogers, R., Bagby, R. M., \& Dickens, S. E. (1992). Structured Interview of Reported Symptoms professional manual. Odessa, Florida: Psychological Assessment Resources.

Rogers, R., Salekin, R. T., Sewell, K. W., Goldstein, A., \& Leonard, K. (1998). A comparison of forensic and nonforensic malingerers: A prototypical analysis of explanatory models. Law and Human Behavior, 22, 353-367.

Rogers, R., Sewell, K. W., Morey, L. C., \& Ustad, K. L. (1996). Detection of feigned mental disorders on the Personality Assessment Inventory: A discriminant analysis. Journal of Personality Assessment, 67, 629-640.

Salekin, R. T., Trobst, K. K., \& Krioukova, M. (2001). Construct validity of psychopathy in a community sample: A nomological net approach. Journal of Personality Disorders, 15, 425-441.

Smith, G. P., \& Burger, G. O. (1997). Detection of malingering: Validation of the Structured Interview of Malingered Symptomology. Journal of the American Academy of Psychiatry and Law, 25, 183-189.

Spitzer, R. L., Williams, J. B.W., \& Gibbons, M. (1987). Structured Clinical Interview for DSMIII-R. New York: Biometrics Research.

Spitzer, R. L., Williams, J. B.W., Gibbons, M., \& First, M. B. (1990). Structured Clinical 
Interview for DSM-III-R_Patient Version (SCID-P, 4/1/88). New York: Biometrics Research Department, New York Stated Psychiatric Institute.

Ustad, K. L., \& Rogers, R. (1996). Malingering and deception: Conceptual and clinical issues in forensic practice. In L. B. Schlesinger (Ed.), Explorations in criminal psychopathology: Clinical syndromes with forensic implications (pp. 300-319). Springfield, IL: Charles C. Thomas.

Vreven, D. L., Gudanowski, D. M., King, L. A., \& King, D. W. (1995). The civilian version of the Mississippi PTSD Scale: A psychometric evaluation. Journal of Traumatic Stress, 8, 91-109.

Weathers, F. W., Litz, B. T., Herman, D. S., Huska, J. A., \& Keane, T. M. (1993, October). The PTSD Checklist (PCL): Reliability, validity, and diagnostic utility. Paper presented at the annual meeting of the International Society for Traumatic Stress Studies, San Antonio, TX. 
Table 1

Cleckley's Sixteen Characteristics of Psychopaths

1. Superficial charm and good intelligence

2. Absence of delusions and other signs of irrational thinking

3. Absence of "nervousness" or psychoneurotic manifestations

4. Unreliability

5. Untruthfulness and insecurity

6. Lack of remorse or shame

7. Inadequately motivated antisocial behavior

8. Poor judgment and failure to learn by experience

9. Pathological egocentricity and incapacity for love

10. General poverty in major affective reactions

11. Specific loss of insight

12. Unresponsiveness in general interpersonal relations

13. Fantastic and uninviting behavior with drink and sometimes without

14. Suicide rarely carried out

15. Sex life impersonal, trivial, and poorly integrated

16. Failure to follow any life plan

Source: Cleckley, H. (1988). The mask of sanity ( ${ }^{\text {th }}$ ed., p. 337-338). 
Table 2

DSM-IV-TR Criteria for Antisocial Personality Disorder

A. There is a pervasive pattern of disregard for and violation of the rights of others occurring since age 15 years, as indicated by three (or more) of the following:

(1) failure to conform to social norms with respect to lawful behaviors as indicated by repeatedly performing acts that are grounds for arrest

(2) deceitfulness, as indicated by repeated lying, use of aliases, or conning others for personal profit or pleasure

(3) impulsivity or failure to plan ahead

(4) irritability and aggressiveness, as indicated by repeated physical fights or assaults

(5) reckless disregard for safety of self or others

(6) consistent irresponsibility, as indicated by repeated failures to sustain consistent work behavior or honor financial obligations

(7) lack of remorse, as indicated by being indifferent to or rationalizing having hurt, mistreated, or stolen from another

B. The individuals is at least age 18 years.

C. There is evidence of Conduct Disorder with onset before age 15 years.

D. The occurrence of antisocial behavior is not exclusively during the course of Schizophrenia or a Manic Episode. 
Table 3

Psychopathy Checklist-Revised (PCL-R) Items

1. Glibness/superficial charm

2. Grandiose sense of self-worth

3. Need for stimulation/proneness to boredom

4. Pathological lying

5. Conning/manipulative

6. Lack of remorse or guilt

7. Shallow affect

8. Callous/lack of empathy

9. $\quad$ Parasitic lifestyle

10. Poor behavioral controls

11. Promiscuous sexual behavior

12. Early behavior problems

13. Lack of realistic, long-term goals

14. Impulsivity

15. Irresponsibility

16. Failure to accept responsibility for actions

17. Many short-term marital relationships

18. Juvenile delinquency

19. Revocation of conditional release

20. Criminal versatility

Source: Hare, R. D. (1991). The Hare Psychopathy Checklist-Revised manual. Toronto, Canada: Multi-Health Systems. 
Table 4

Demographics of Participants by Group

Group

Clinical Controls

Malingerers

Comparison Psychopathic Nonpsychopathic

$\begin{array}{ccc}n=8 & n=24 & n=24 \\ n \% & n \% & n \%\end{array}$

Category

n

$\%$

$\%$

Age

$\begin{array}{cccc}18 & 3(37.5 \%) & 3(12.5 \%) & 6(25.0 \%) \\ 19 & 2(25.0 \%) & 10(41.7 \%) & 6(25.0 \%) \\ 20 & 2(25.0 \%) & 6(25.0 \%) & 5(20.8 \%) \\ 21 & 1(12.5 \%) & 1(4.2 \%) & 3(12.5 \%) \\ 22 & 0 & 2(8.3 \%) & 1(4.2 \%) \\ 23 & 0 & 2(8.3 \%) & 1(4.2 \%) \\ 24 & 0 & 0 & 1(4.2 \%) \\ 30 & 0 & 0 & 1(4.2 \%)\end{array}$

Race

$\begin{array}{cccc}\text { Caucasian } & 7(87.5 \%) & 19(79.2 \%) & 18(75.0 \%) \\ \text { African American } & 0 & 3(12.5 \%) & 4(16.7 \%) \\ \text { Asian American } & 1(12.5 \%) & 1(4.2 \%) & 1(4.2 \%) \\ \text { Other } & 0 & 1(4.2 \%) & 1(4.2 \%)\end{array}$

Year in School 


$\begin{array}{cccc}\text { First } & 4(50.0 \%) & 6(25.0 \%) & 6(25.0 \%) \\ \text { Second } & 2(25.0 \%) & 11(45.8 \%) & 10(41.7 \%) \\ \text { Third } & 1(12.5 \%) & 4(16.7 \%) & 3(12.5 \%) \\ \text { Fourth } & 1(12.5 \%) & 1(4.2 \%) & 3(12.5 \%) \\ \text { Fifth or Higher } & 0 & 2(8.3 \%) & 2(8.3 \%)\end{array}$

GPA

$\begin{array}{cccc}1.51-1.75 & 0 & 1(4.2 \%) & 0 \\ 1.76-2.00 & 1(12.5 \%) & 1(4.2 \%) & 2(8.3 \%) \\ 2.01-2.25 & 0 & 1(4.2 \%) & 2(8.3 \%) \\ 2.26-2.50 & 2(25.0 \%) & 2(8.3 \%) & 1(4.2 \%) \\ 2.51-2.75 & 0 & 5(20.8 \%) & 6(25.0 \%) \\ 2.76-3.00 & 2(25.0 \%) & 3(12.5 \%) & 3(12.5 \%) \\ 3.01-3.25 & 0 & 4(16.7 \%) & 2(8.3 \%) \\ 3.26-3.50 & 3(37.5 \%) & 5(20.8 \%) & 5(20.8 \%) \\ 3.51-3.75 & 0 & 0 & 0 \\ 3.76-4.0 & 0 & 1(4.2 \%) & 2(8.3 \%) \\ \text { Did Not Report } & 0 & 1(4.2 \%) & 1(4.2 \%)\end{array}$

Legal Conflicts

$\begin{array}{llll}\text { No } & 7(87.5 \%) & 14(58.3 \%) & 21(87.5 \%) \\ \text { Yes } & 1(12.5 \%) & 10(41.7 \%) & 3(12.5 \%)\end{array}$

Legal Situation

$\begin{array}{cccc}\text { None } & 7(87.5 \%) & 14(58.3 \%) & 21(87.5 \%) \\ \text { Alcohol } & 0 & 5(20.8 \%) & 0\end{array}$


Psychopathy and Malingering 51

$\begin{array}{lccc}\text { Drug } & 0 & 3(12.5 \%) & 2(8.3 \%) \\ \text { Other } & 1(12.5 \%) & 2(8.3 \%) & 1(4.2 \%)\end{array}$

Legal

Consequences

$\begin{array}{cccc}\text { None } & 8(100 \%) & 19(79.2 \%) & 22(91.7 \%) \\ \text { Probation } & 0 & 4(16.7 \%) & 2(8.3 \%) \\ \text { Jail Time } & 0 & 1(4.2 \%) & 0\end{array}$


Table 5

Administrator Measures: SIP and ARB Total Score by Group

Group

Clinical Controls

Malingerers

Comparison Psychopathic Nonpsychopathic
$n=8$
$n=24$
$n=24$

\begin{tabular}{cccccccc} 
Measure & Mean & $(\mathrm{SD})$ & Mean & $(\mathrm{SD})$ & Mean & $(\mathrm{SD})$ & $F(2,55)$ \\
\hline SIP & 29.75 & $(9.95)$ & 26.04 & $(8.36)$ & 22.92 & $(10.96)$ & 1.610 \\
ARB & 8.50 & $(3.16)$ & 8.54 & $(3.43)$ & 8.63 & $(2.57)$ & 0.007
\end{tabular}

Note. SIP = The Structured Interview for PTSD Scale; ARB = Administrator Rating of Believability Questionnaire. 
Table 6

Self-Report Measure: DAPS Total Score and Subscale Score by Group

\section{Group}

Clinical Controls

Comparison Psychopathic Nonpsychopathic
$n=8$
$n=24$
$n=24$

Malingerers

Measure

Mean (SD)

Mean

(SD)

Mean (SD)

$F(2,55)$

DAPS PB

$0.50^{\mathrm{a}} \quad(0.53)$

1.21

(1.72)

$2.50^{\mathrm{b}}$

(2.54)

$3.963^{*}$

DAPS NB

12.75

(3.01)

12.42

(2.95)

11.96

(4.77)

0.158

DAPS ST

105.75

(17.25)

95.50

(25.28)

89.46

(23.88)

1.458
$12.87 \quad(4.82)$
DAPS IMP
16.38
(5.18)
$14.50 \quad(4.97)$
1.668

(4.82)

Note. DAPS = Detailed Assessment of Posttraumatic Stress; PB = Positive Bias; NB = Negative Bias; ST =

Posttraumatic Stress; IMP = Posttraumatic Impairment. Means in the same row that do not share superscripts differ.

$* p<.05$ 
Psychopathy and Malingering 54

Table 7

Number of Participants That Successfully Avoided Detection of Malingering PTSD on the DAPS by Group

\section{Group}

Clinical Controls

Malingerers

Comparison Psychopathic Nonpsychopathic

DAPS Profile

$n \%$

$n \%$

$n \%$

Valid and Elevated

Yes

$2(25.0 \%)$

$4(16.7 \%)$

$3(12.5 \%)$

No

$6(75.0 \%)$

$20(83.3 \%)$

$21(87.5 \%)$

Note. DAPS $=$ Detailed Assessment of Posttraumatic Stress. 
Psychopathy and Malingering 55

Table 8

Self-Report Interpersonal Measures: CQ and FLL Score by Group

Group

Clinical Controls

Malingerers

Comparison Psychopathic Nonpsychopathic
$n=8$
$n=24$
$n=24$

\begin{tabular}{cccccccc} 
Measure & Mean & $(\mathrm{SD})$ & Mean & $(\mathrm{SD})$ & Mean & $(\mathrm{SD})$ & $F(2,55)$ \\
\hline CQ & 7.13 & $(2.23)$ & 7.58 & $(1.89)$ & 7.83 & $(1.74)$ & 0.439 \\
FLL & 11.50 & $(2.78)$ & $11.29^{\mathrm{b}}$ & $(3.16)$ & $13.54^{\mathrm{a}}$ & $(2.41)$ & $4.228^{*}$
\end{tabular}

Note. $\mathrm{CQ}=$ Confidence Questionnaire; FLL = Future Likelihood of Lying Questionnaire. Means in the same row that do not share superscripts differ.

$* p<.025$ 
Psychopathy and Malingering 56

Appendix A

Recruitment Flyers and Sign-Up Sheets 


\section{Are you an ADVENTUROUS, RISKY DAREDEVIL? Are you CAREFUL, PREDICTABLE \& RESERVED? Can you Fool the Experts?}

Title of Research Project:

Examining Personality Characteristics and Posttraumatic Stress Disorder (PTSD) from a Motor Vehicle Accident

\section{Purpose:}

This study examines how different personality characteristics allow the effectiveness of individuals to fake posttraumatic stress disorder (PTSD) as a result of a motor vehicle accident. Not all participants will be asked to fake PTSD.

Participation will take approximately 100-120 minutes. Participants will receive extra credit for psychology courses and all may have the opportunity to earn $\mathbf{\$ 1 0 0 . 0 0}$. Monetary prizes will be determined by successfully faking and convincing researchers of having PTSD during interviews and on an assessment measure while pretending to be involved in a civil law suit from a motor vehicle accident. For successful participants, a lottery system will be utilized to select two individuals to each win a prize of $\$ 100.00$.

\section{Criteria for Eligibility:}

Only MALE participants will be used in this study.

Any enrolled WVU male student is eligible.

\section{Location:}

Fill out the sign-up sheet posted on the bulletin board on the first floor of the Life Sciences Building. The study will take place in rooms 1321 and 1323 of the LSB.

\section{Investigators:}

Elizabeth A. Tyner, B.S., graduate student in adult clinical psychology, Office \# 1224 LSB, 304-293-2001

William Fremouw, Ph.D., faculty advisor 
Please read the following to your psychology class and pass around: Are you an ADVENTUROUS, RISKY DAREDEVIL? Are you CAREFUL, PREDICTABLE \& RESERVED? Can you Fool the Experts?

Title of Research Project:

\author{
Examining Personality Characteristics and Posttraumatic Stress Disorder (PTSD) \\ from a Motor Vehicle Accident
}

\title{
Purpose:
}

This study examines how different personality characteristics allow the effectiveness of individuals to fake posttraumatic stress disorder (PTSD) as a result of a motor vehicle accident. Not all participants will be asked to fake PTSD.

Participation will take approximately 100-120 minutes. Participants will receive extra credit for psychology courses and all may have the opportunity to earn $\mathbf{\$ 1 0 0 . 0 0}$. Monetary prizes will be determined by successfully faking and convincing researchers of having PTSD during interviews and on an assessment measure while pretending to be involved in a civil law suit from a motor vehicle accident. For successful participants, a lottery system will be utilized to select two individuals to each win a prize of $\$ 100.00$.

\section{Criteria for Eligibility:}

Only MALE participants will be used in this study.

Any enrolled WVU male student is eligible.

\section{Location:}

Fill out the sign-up sheet posted on the bulletin board on the first floor of the Life Sciences Building. The study will take place in rooms 1321 and 1323 of the LSB.

\section{Investigators:}

Elizabeth A. Tyner, B.S., graduate student in adult clinical psychology,

Office \# 1224 LSB, 304-293-2001

William Fremouw, Ph.D., faculty advisor

$* * * * *$ Please write down the time, date and location that you signed-up to participate. Many students forget this information!!!! 
To sign up for this study, please write down your name and phone \#.

This study takes place in Rooms $\mathbf{1 3 2 1}$ and $\mathbf{1 3 2 3}$ of the LSB. ***Reminder: This study is for MALES only!

\begin{tabular}{|c|c|c|c|}
\hline \multicolumn{2}{|r|}{$\begin{array}{c}\text { Monday } \\
03 / 21\end{array}$} & \multicolumn{2}{|r|}{$\begin{array}{c}\text { Tuesday } \\
03 / 22\end{array}$} \\
\hline & Phone \# & & Phone\# \\
\hline 12:30pm & & 9:00am & \\
\hline $12: 45$ & & 9:15 & \\
\hline 1:00 & & 9:30 & \\
\hline 1:15 & & $9: 45$ & \\
\hline $1: 30$ & & 10:00 & \\
\hline 1:45 & & $10: 15$ & \\
\hline 2:00 & & $10: 30$ & \\
\hline $2: 15$ & & $10: 45$ & \\
\hline $2: 30$ & & & \\
\hline $2: 45$ & & & \\
\hline 3:00 & & & \\
\hline $3: 15$ & & & \\
\hline 3:30 & & & \\
\hline 3:45 & & & \\
\hline 4:00 & & & \\
\hline 4:15 & & & \\
\hline 4:30 & & & \\
\hline
\end{tabular}


To sign up for this study, please write down your name and phone \#.

This study takes place in Rooms $\mathbf{1 3 2 1}$ and $\mathbf{1 3 2 3}$ of the LSB.

***Reminder: This study is for MALES only!

\begin{tabular}{|c|c|c|c|}
\hline \multicolumn{2}{|r|}{$\begin{array}{c}\text { Wednesday } \\
03 / 23\end{array}$} & \multicolumn{2}{|r|}{$\begin{array}{c}\text { Thursday } \\
03 / 24\end{array}$} \\
\hline & Phone\# & & Phone\# \\
\hline $12: 30$ & & $5: 30$ & \\
\hline $12: 45$ & & $5: 45$ & \\
\hline 1:00 & & 6:00 & \\
\hline $1: 15$ & & $6: 15$ & \\
\hline $1: 30$ & & $6: 30$ & \\
\hline $1: 45$ & & & \\
\hline $2: 00$ & & & \\
\hline $2: 15$ & & & \\
\hline $2: 30$ & & & \\
\hline $2: 45$ & & & \\
\hline $3: 00$ & & & \\
\hline $3: 15$ & & & \\
\hline $3: 30$ & & & \\
\hline $3: 45$ & & & \\
\hline 4:00 & & & \\
\hline $4: 15$ & & & \\
\hline $4: 30$ & & & \\
\hline
\end{tabular}


Psychopathy and Malingering 61

Appendix B

Phase One Measure 
DEMOGRAPHIC DATA

1. Date of Birth:

2. Age:

(in years)

3. Current GPA:
4. Marital Status: Single

Married

Separated
5. Race:

6. Current year in school:

${ }^{1 \mathrm{st}}$
${ }^{\mathrm{nd}}$
$3^{\mathrm{rd}}$
$4 \mathrm{th}$

7. Religion:

Baptist

Jewish

Catholic

Lutheran

Christian Reformed Methodist

Episcopal

Presbyterian

None

Other (please specify)
Asian-American

American Indian

Pacific Islander

Mulitracial (please specify)

Other (please specify)
ID \#

Divorced
African-American

Hispanic

Alaskan Native

International/Non-US Resident
8. Have you ever had any legal conflicts? yes no

9. If yes, check all consequences that apply and list time served:

probation months jail time months prison time months

Briefly describe the offense and situation 
Psychopathy and Malingering 63

\section{Appendix C}

Phase Two Instructions and Measures 


\section{Instructions for PHASE 2}

For the next portion of this study, you will make up a story about a motor vehicle accident (car accident).

Use your imagination!

You may expand on past knowledge of car accidents.

\section{Be sure that your story is}

credible and believable.

The research assistant in Phase Two will not know which instructions that you have been given.

Do not tell her which instructions you have seen!

If you have any questions, ask the research assistant from this Phase One before you begin Phase Two. 


\section{Instructions for PHASE 2}

\section{For the next portion of this study, you will use your story about your traumatic motor vehicle accident (car accident).}

The research assistant in Phase Two will not know which instructions that you have been given.

Do not tell her which instructions you have seen!

If you have any questions, ask the research assistant from this Phase One before you begin Phase Two. 


\section{Instructions for Hypothetical MVA Civil Litigation Scenario}

In this study, we are investigating how well people can tell others a story about a motor vehicle accident (MVA). Therefore, please complete this portion of the study (Phase Two) as you were instructed at the end of Phase One.

\section{Remember that I do not know what instructions were given to you.}

When completing this phase, pretend that you were involved in a motor vehicle accident in which you were seriously injured. Although your automobile and hospital bills are paid by insurance, you could win up to $\$ 100,000.00$ through a civil litigation for your current "pain and suffering."

In order to win this $\$ 100,000.00$, you need to convince the forensic psychologist ("ME") that you are CURRENTLY suffering from posttraumatic stress disorder (PTSD). PTSD is the name of a psychological disorder that individuals may develop that is caused by exposure to a traumatic event such as a motor vehicle accident. When someone has PTSD they are in extreme emotional distress.

You will have two minutes to prepare your story. I will leave the room during those two minutes. After I return to the room, I will start recording on the video camera and you will have two minutes to tell your story. While you tell your story, I will signal when one minute remains and when 30 seconds remain.

\section{Remember that you are pretending that you are currently experiencing pain and suffering.}

\section{Be sure that your story is believable and credible!}

After you tell your story, you will be answering more questions about the MVA. It is important to pretend that you are in a civil litigation case for your MVA.

After that, you will fill out a few more questionnaires about your experiences during this research study.

The top two most convincing participants will actually win $\$ 100$.You will have an opportunity to provide us with your email address so that we may contact you if you are one of the two most successful!

Do you have any questions? 


\section{Administrator Rating of Believability Questionnaire}

Rate how believable the participant was throughout Phase Two.

****Questions $1 \& 2$ are answered after 2 minute presentation.****

1. The participant made me TRULY BELIEVE what he was saying.

1 Strongly Agree

2 Agree

3 Disagree

4 Strongly Disagree

2. The participant did a good job of making me believe that he was totally sincere.

1 Strongly Agree

2 Agree

3 Disagree

4 Strongly Disagree

****Questions $3 \& 4$ are answered after the SIPS interview.****

3. The participant made me TRULY BELIEVE what he was saying.

1 Strongly Agree

2 Agree

3 Disagree

4 Strongly Disagree

4. The participant did a good job of making me believe that he was totally sincere.

1 Strongly Agree

2 Agree

3 Disagree

4 Strongly Disagree 


\section{Now you will fill out the next 104 item questionnaire called the DAPS.}

When taking this, please pretend as if you are still in the hypothetical civil litigation scenario.

Answer as if you are attempting to convince the forensic psychologist that you have PTSD from your motor vehicle accident.

\section{Remember: The 2 most successful participants will actually win $\$ 100$.}




\section{DAPS Instructions}

-Skip Part 1 (Questions 1-13)

-Answer question \# 14 just as you described your story in Phase Two

-Answer this entire DAPS questionnaire form about your reactions to the motor vehicle accident that described in Phase Two

-Remember that you are still pretending to be in the civil litigation scenario. You are still trying to convince the forensic psychologist that you are currently experiencing "pain and suffering" and PTSD from this motor vehicle accident 
These last 3 questionnaires are on yellow, blue and green paper.

\section{These forms ask you about your experiences as a participant in this research study.}

You are NO LONGER pretending to be in a civil scenario.

Please answer these 3 forms

TRUTHFULLY,

as how you

feel in real life. 


\section{Self-Report Confidence Questionnaire}

Please evaluate your performance today. For each of the following statements, please circle the number that best describes your opinion.

1. I am confident that I made the observer TRULY BELIEVE what I was saying.

1 Strongly Agree

2 Agree

3 Disagree

4 Strongly Disagree

2. I did a good job of making the observer believe that I was totally sincere.

1 Strongly Agree

2 Agree

3 Disagree

4 Strongly Disagree

3. I enjoyed trying to make the observer believe that I was totally sincere.

1 Strongly Agree

2 Agree

3 Disagree

4 Strongly Disagree

4. I felt that participating in this experiment was a positive experience.

1 Strongly Agree

2 Agree

3 Disagree

4 Strongly Disagree 


\section{Future Likelihood of Lying Questionnaire}

For each of the following statements, please circle the number that best describes your opinion.

1. I have been known to lie in my lifetime.

1 Strongly Agree

2 Agree

3 Disagree

4 Strongly Disagree

2. I lie frequently.

1 Strongly Agree

2 Agree

3 Disagree

4 Strongly Disagree

3. I will most likely lie again in the future.

1 Strongly Agree

2 Agree

3 Disagree

4 Strongly Disagree

4. For this question, rate the best answer to describe how often you lie:

1 More than once per day

2 Once per day

3 A couple times per week

4 Once per week

5 Less than once per week

6 Never 


\section{Criteria Checklist}

1. Please indicate (make an ' $\mathbf{X}$ ') which instructions you were given prior to starting Phase Two:

$* * * *$ I pretended like I was in a civil litigation where I could have won $\$ 100,000.00$ because of a serious motor vehicle accident. While I was pretending to participate in this hypothetical scenario,

I was instructed to truthfully tell the observer my MVA story.

I was instructed to make up a story that was NOT TRUE about a MVA.

2. If you could participate in this experiment again, what would you do differently?

3. How important to you is winning $\mathbf{\$ 1 0 0}$ for participating in this study?

1 Not at all important

2 Somewhat important

3 Important

4 Extremely important 


\section{Contact Information Form (Please print clearly)}

Email Address 
Psychopathy and Malingering 75

Appendix D

Consent Forms 


\section{CONSENT AND INFORMATION FORM}

Title: Examining Personality Characteristics and Posttraumatic Stress Disorder from a Motor Vehicle Accident

Investigators: Elizabeth A. Tyner, B.S., and William Fremouw, Ph.D., West Virginia University

Introduction: I, , have

been invited to participate in this research study, which has been explained to me by

This research is being conducted by Elizabeth A. Tyner, B.S. to fulfill the requirements for a master's thesis in the Department of Psychology at West Virginia University, under the supervision of William Fremouw, Ph.D.

Purpose of the Study: This study is designed to examine the effect of personality characteristics on posttraumatic stress disorder (PTSD) from a motor vehicle accident (MVA).

Description of Procedures: For the first portion of this study, which will take about 50-60 minutes, I will be asked to complete the 49-item Posttraumatic Stress Diagnostic Scale (PDS) regarding the existence and nature of previous traumas and any psychological consequences of existing traumas. The PDS takes approximately 10 minutes to complete. Then, I will be asked to complete the 56-item Psychopathic Personality Inventory (PPI) to assess the nature of the personality traits that I possess. The PPI takes approximately 30 minutes to complete. Next, I will be asked to complete a basic demographic questionnaire which takes approximately 5 minutes to complete. I will be asked to respond either honestly to the next three assessments in the second portion or as if I had experienced a motor vehicle accident.

The second portion of the study, which will follow immediately after the first portion, will take approximately 50 minutes to complete. First, a hypothetical civil litigation scenario will be read to me by a researcher, and I will be asked to answer the next three assessments with the goal of convincing the administrator that I am suffering from PTSD from a MVA to gain $\$ 100,000.00$ for "pain and suffering." Then, I will be asked to be individually interviewed and videotaped while I give a two minute story (honest or as if I had experienced a motor vehicle accident); also I will be asked to be interviewed and videotaped during the 17-item Structured Interview for Posttraumatic Stress Disorder (SIP) (honest or as if I had experienced a motor vehicle accident). The SIP also examines the existence and nature of previous traumas and any psychological consequences of existing traumas; it takes approximately 20 minutes to administer. Next, I will be asked to complete the Detailed Assessment of Posttraumatic Stress Disorder (DAPS) while answering as I was instructed for the last two interview assessment. The 104-item DAPS takes approximately 20 minutes to complete and also examines the existence and nature of previous traumas and any psychological consequences of existing traumas.

Submission Date $\underline{10-11-04} \quad$ Page 1 of 3

$\overline{\text { Initials }} \quad \overline{\text { Date }}$ 
Title: Examining Personality Characteristics and Posttraumatic Stress Disorder from a Motor Vehicle Accident

For the final portion of the study, I will complete three additional measures while answering honestly, no matter how I was previously instructed. I will complete three brief measures: the four-item Confidence questionnaire, the four-item Future Likelihood of Lying questionnaire, and the three-item criteria checklist. This final portion of the study will take approximately 5 minutes to complete, totaling 100-120 minutes for the entire study. I understand that I am not required to answer all of the questions and that I may view the questions before signing the consent for if I request to do so. My participation in this study will not affect my grades or standing in class, and alternative options are available for obtaining extra credit. Approximately 200 student participants will be involved in this study, with 40 participants being selected from those with low PDS scores (no PTSD) and 40 participants being selected from those with high PDS scores (indicating PTSD).

Risks and Discomforts: There are no known or expected risks from participating in this study, aside from time associated with completing the questionnaires and mild discomfort that may arise in response to being asked about psychological symptoms and personal experiences. I understand that all participants will be provided with a list of local mental health resources.

Alternatives: I may choose not to participate in this study. I have been advised by Elizabeth A. Tyner, B.S. that participation is voluntary, am I am free to decline participation or discontinue participation at any time. My participation in this study will not affect my grades or standing in class, and alternative options are available for obtaining extra credit. All data are considered confidential.

Benefits: I understand that this study is not expected to be of direct benefit to me, but the knowledge gained may be of benefit to others. I will receive extra credit in my Psychology class for participation, but there are other ways I may earn extra credit.

Financial Considerations: I am eligible, but not guaranteed, the opportunity to win $\$ 100.00$ as a result of my participation. If I am asked to respond as if I had experienced a motor vehicle accident, the monetary reward will be based on successfully avoiding detecting of malingering on the DAPS and obtaining a clinically elevated score on the SIP and presenting my made-up story in a convincing and believable manner. If I am asked to respond honestly, the monetary reward will be based on successfully avoiding detecting of malingering on the DAPS and obtaining a clinically elevated score on the SIP and presenting my true story in a convincing and believable manner. The two most successful subject names from each group (made-up story and honest) will be placed in two separate lotteries. One name from each group will be drawn; each of those individuals will win the $\$ 100.00$ prize.

Submission Date 10-11-04

Page 2 of 3 
Title: Examining Personality Characteristics and Posttraumatic Stress Disorder from a Motor Vehicle Accident

Contact Persons: For more information about this research, I can contact Elizabeth A. Tyner, B.S. or her supervisor, William Fremouw, Ph.D., at 293-2001 ext. 31662. For information regarding my rights as a research subject, I may contact the Office of Research Compliance at 304/293-7073.

Confidentiality: I understand that any information about me obtained as a result of my participation in this research will be kept as confidential as legally possible. I understand that my research records, test results, and videotapes, just like hospital records, may be subpoenaed by court order or may be inspected by the study sponsor or federal regulatory authorities (including the FDA if applicable) without my additional consent. In any publications that result from this research, neither my name nor any information from which I may identified will be published without my consent. The paper data and videotapes will be kept in a locked laboratory in the Life Sciences Building until 5 years after the publication of the results. WVU staff will then shred the raw data and erase all videotapes.

Voluntary Participation: Participation in this study is voluntary. I understand that I am free to withdraw my consent to participate in this study at any time and that such refusal to participate will not affect my class standing or grades at West Virginia University. Refusal to participate or withdrawal will involve no penalty to me. I have been given the opportunity to ask questions about the research, and I have received answers concerning areas I did not understand. In the even new information becomes available that may affect my willingness to continue to participate in the study, this information will be given to me so that I may make an informed decision about my participation.

Upon signing this form, I will receive a copy.

I willingly consent to participate in this research.

Signature of Subject

Signature of Investigator or Co-Investigator

Submission Date $\underline{10-11-04} \quad$ Page 3 of 3

\section{$\overline{\text { Date }} \overline{\text { Time }}$}

$\overline{\text { Date }} \overline{\text { Time }}$




\section{Authorization to Use or Disclose Protected Health Information (PHI)}

\section{West Virginia University}

I hereby voluntarily authorize the use or disclosure of my individually identifiable health information as described below.

Patient Name:

Date of Birth:
ID Number:

IRB Protocol \#:

Persons/organizations providing the protected health information (e.g. hospitals):

Research participants

Persons/organizations receiving the information (e.g. investigators, clinical coordinators, sponsor, FDA):

Elizabeth A. Tyner, B.S. and William Fremouw, Ph.D., Investigators

The following information will be used:

Gender, date of birth, age, race, marital status, year in school, religious affiliation, psychiatric treatment history, legal conflicts, trauma history, results and interpretations of tests

The information is being disclosed for the following purposes (Start with the Title of the study and include additional information e.g. screening and recruiting subjects; analyzing research data, or other specified purposes):

Screening and recruiting subjects; Analyzing research data

I may revoke this authorization at any time by notifying the Principal Investigator in writing at:

Elizabeth A. Tyner

PO BOX 6040

53 Campus Drive

Morgantown, WV 26506-6040

Phone: 293-2001 ext. 31662

If I do revoke my authorization, any information previously disclosed cannot be withdrawn. Once information about me is disclosed in accordance with this authorization, the recipient may redisclose it and the information may no longer be protected by federal privacy regulations. 


\section{Authorization to Use or Disclose Protected Health Information (Contd.)}

I may refuse to sign this authorization form. My clinical treatment may not be affected by whether or not I sign this form. I may not be allowed to participate in the research if I do not sign the form.

This authorization will expire on the date that the research study ends. (Other options for expiration include an actual date of expiration, occurrence of a particular event, or "none" if the authorization will have no expiration date.)

Expiration date: $\quad$ Estimated to be

December 31, 2005

I will be given a copy of this authorization form.

Signature of subject or subject's legal representative

Date

(Form MUST be completed before signing)

Printed name of subject's legal representative

Relationship to the subject

Initials

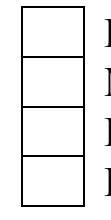

Parent

Medical power of attorney/representative

Legal guardian

Health care surrogate 
Psychopathy and Malingering 81

Appendix E

Debriefing Forms 


\section{End of Research Study Debriefing Form}

The purpose of this research study was to examine how personality characteristics allow the effectiveness of individuals to fake posttraumatic stress disorder (PTSD) as a result of a motor vehicle accident.

All participants were instructed to pretend to be a hypothetical civil litigation scenario and the goal was to convince the forensic psychologist (the researcher) that they had PTSD and were experiencing "pain and suffering" due to the motor vehicle accident in order to win $\$ 100,000.00$.

In real life, the participants in the research study will have the opportunity to actually win $\$ 100$.

Prizes will be given to the most successful participants. Success is determined by being the most believable and credible during the interview and also by being convincing on the self-report DAPS questionnaire. For those successful participants, a lottery system will be used to select two winners of $\$ 100$. Winners will be notified by email when this study is completed. Completion of this study may occur during Fall 2004, or Spring 2005.

Before you leave this research study, please take the following four forms with you:

\section{Local Mental Health Resources \\ Copy of Consent form \\ Copy of PHI form \\ Extra Credit Participation Slip}

Please discuss any questions with the research assistant.

Additionally, please notify the research assistants if you are experiencing any distress as a result of participating in this study.

If you have any further questions, please contact Elizabeth Tyner at: etyner@mix.wvu.edu or 293-2001.

THANK YOU FOR YOUR PARTICIPATION IN THIS STUDY. 


\section{LOCAL MENTAL HEALTH RESOURCES}

Because completion of surveys, such as the ones you just did, may make some persons realize that they are experiencing an uncomfortable level of worry or depression. The investigators in this study are providing participants with this list of several local mental health and counseling services that are available to them if they feel that they would like to talk with someone about their feelings. Additionally, participants may contact Elizabeth Tyner, B.S. or William Fremouw, Ph.D. at 293-2001 ext. 31662 for a copy of this list.

This is a partial list of services in the Morgantown area, for cases in which you feel that you need assistance. Inclusion on this list does NOT imply endorsement of the agency by the investigators of this study, nor does it imply that the investigators are financially responsible for any services requested or received as a result of participation in this study.

\section{Carruth Center for Counseling and Psychological Services*}

Student Services Center

West Virginia University

Morgantown, WV 26506

(304)293-4431

\section{Chestnut Ridge Hospital}

930 Chestnut Ridge Road

Morgantown, WV 26505

(304) 293-4000

\section{The Quin Curtis Center}

Life Sciences Building, Department of Psychology

West Virginia University Morgantown, WV 26506

(304)293-2001 ext. 31671

\section{Valley Comprehensive Community Mental Health Center}

301 Scott Avenue

Morgantown, WV 26505

(304)296-1731

\section{The Vet Center (military veterans only)}

Greenbag Road

Morgantown, WV 26505

(304)291-4303

* Students who have paid WVU tuition and Activities Fee B may receive services free of charge at this agency. 
Psychopathy and Malingering 84

\section{Appendix F}

Participation Record and Payment Invoice 


\section{PARTICIPATION RECORD SLIP \\ (complete in INK)}

I have participated in the following study conducted in the Psychology Department at West Virginia University:

Study Title: Examining Personality Characteristics and Posttraumatic Stress Disorder (PTSD) from a Motor Vehicle Accident.

Study \#: 152

Date of Participation:

Number of hours of participation:

Participant Name (printed):

Researcher Name (printed):

Researcher Name (signed):

\section{PARTICIPATION RECORD SLIP \\ (complete in INK)}

I have participated in the following study conducted in the Psychology Department at West Virginia University:

Study Title: Examining Personality Characteristics and Posttraumatic Stress Disorder (PTSD) from a Motor Vehicle Accident.

Study \#: 152

Date of Participation: Number of hours of participation:

Participant Name (printed):

Researcher Name (printed):

Researcher Name (signed): 
Forensic Psychology Laboratory

Research Invoice

\begin{tabular}{|l|l|}
\hline Invoice Date & \\
\hline Department Name & Psychology \\
\hline
\end{tabular}

\begin{tabular}{|l|l|}
\hline \multicolumn{2}{|c|}{ PARTICIPANT INFORMATION } \\
\hline Participant Name & \\
\hline Mailing Address & \\
\hline Participant Social Security Number & \\
\hline Participant Signature & \\
\hline
\end{tabular}

TITLE OF STUDY: Examining Personality Characteristics and PTSD from a Motor Vehicle Accident PRINCIPAL INVESTIGATOR: $\quad$ Elizabeth A. Tyner, B. S.

CO-INVESTIGATOR: $\quad$ William Fremouw, Ph.D.

\begin{tabular}{|l|l|l|l|}
\hline \multicolumn{1}{|c|}{ Quantity } & \multicolumn{1}{|c|}{ Description } & Unit Price & Extended Price \\
\hline 1 & $\begin{array}{l}\text { Research Participation } \\
\text { From Date } \\
\text { To Date }\end{array}$ & $\$ 100.00$ & $\$ 100.00$ \\
\hline & & TOTAL & $\$ 100.00$ \\
\hline
\end{tabular}

\begin{tabular}{|c|c|c|c|}
\hline Project & Task & Award & Amount \\
\hline & & & $\$ 100.00$ \\
\hline & & TOTAL & $\$ 100.00$ \\
\hline
\end{tabular}

\begin{tabular}{|l|l|}
\hline Research Staff's Signature & \\
\hline Account Manager's Signature & \\
\hline Budget Officer's Signature & \\
\hline
\end{tabular}




\section{Elizabeth A. Tyner}

\section{Curriculum Vitae \\ August, 2005}

\section{Personal Information}

Psychology Department

West Virginia University

53 Campus Drive

1124 Life Sciences Building

Morgantown, WV 26506-6040

\section{Education}

\section{8/05-current West Virginia University}

Ph.D. candidate, Clinical Psychology

Emphasis: Forensic Psychology

Advisor: William J. Fremouw, Ph.D.

8/03-8/05 West Virginia University

M.S., Clinical Psychology

Emphasis: Forensic Psychology

Thesis: "The Relation of Psychopathic Characteristics and Malingering of PTSD"

Advisor: William J. Fremouw, Ph.D.

8/98-4/02 Western Michigan University

B.S., Psychology

Minor: Spanish

Magna Cum Laude

Honors Thesis: "Individuals with Psychopathic Characteristics in a Nonclinical

Population: Using a Stroop Color-Word task to Identify Meaningful Words"

\section{Educational Honors and Awards}

Psi Chi National Honors Society in Psychology, WMU

Who's Who Among Student Students in American Universities

Dean's list, WMU

WMU Achievement Scholarship Award

Lee Honors College (WMU)

Golden Key International Honour Society, WMU

Alpha Lambda Delta National Academic Honor Society, WMU

WMU Greek Woman of the Year Award

\section{Research Experience}

Fremouw, W., Strunk, J., Tyner E., \& Musick, R. (in progress). Adolescent suicide assessment protocol light (ASAP-12). West Virginia Department of Health and Human Resources Grant.

Fremouw, W., Strunk, J., Tyner E., \& Musick, R. (2003). Adolescent suicide assessment protocol (ASAP-20). West Virginia Department of Health and Human Resources Grant. 
Tyner, E. A., \& Fremouw, W. J. (manuscript in preparation). The relation of psychopathic characteristics and malingering of PTSD.

Tyner, E., \& Wright, L. (manuscript in preparation). Individuals with psychopathic characteristics in a nonclinical population: Using a Stroop Color-Word task to identify meaningful words.

Hill, T., Fremouw, W., Patrick, J. \& Tyner, E. (in progress). The effects of ideal body images presented in advertisements on male body esteem.

McCoy, K., Fremouw, W., \& Tyner, E. (in progress). The relationship between illegal behavior and criminal thinking styles.

\section{Publications}

Fremouw, W., Johannsson-Love, J., Tyner, E. A., \& Strunk, J. (in press). Ethical/legal issues in adult assessment. In M. Hersen (Ed.), Comprehensive handbook of behavioral assessment: Vol. 1, Adult assessment. San Diego, CA: Elsevire Press.

Fremouw, W., Strunk, J., \& Tyner, E. (in press). ASAP-20. A guided clinical interview for adolescent suicide assessment. Innovations in Clinical Practice.

Tyner, E. A., \& Wright, L. (2002). Individuals with psychopathic characteristics in a nonclinical population: Using a Stroop Color-Word task to identify meaningful words. Abstract published in the program for the Association for the Advancement of Behavior Therapy $36^{\text {th }}$ annual meeting, November 2002. Reno, Nevada.

\section{Presentations}

Fremouw, W., Strunk. J., Tyner, E. (2005). Assessment of adolescent and adult depression. Sponsored by West Virginia Division of Behavioral Health. Invited presenter, Sharpe Hospital, Weston, WV May 12, 19, and June 2, 2005.

Fremouw, W., Strunk, J., Tyner E., \& Musick, R. (2003). Adolescent suicide assessment protocol (ASAP-20). West Virginia Department of Health and Human Resources. Invited presenter, Charleston, West Virginia, May 20-21, 2004.

Coker, K., Strunk, J., Tyner, E., Fremouw, W. (March, 2005). The ability of naïve versus clinical posttraumatic stress disorder (PTSD) participants to generate and identify symptoms of PTSD. Poster presented at the American Psychology-Law Society Conference. San Diego, CA.

Johannsson-Love, J., Tyner, E., \& Fremouw, W. (March, 2004). Issues surrounding a relationship break-up in a college population. Poster presented at the American Psychology-Law Society Conference. Scottsdale, AZ,

Tyner, E. A., \& Wright, L. (November, 2002). Individuals with psychopathic characteristics in a nonclinical population: Using a Stroop Color-Word Task to identify meaningful words. Poster presented at the Association for the Advancement of Behavior Therapy $36^{\text {th }}$ annual meeting, Reno, Nevada.

\section{Clinical Experience}

William R. Sharpe, Jr. Hospital - Weston, West Virginia

Position: $\quad$ Psychology Intern

Duration: July 2005-June 2006 
Duties: $\quad$ Provide assessment and therapeutic services to persons with

Psychopathy and Malingering 89

severe mental illness

Supervisors: $\quad$ G. David Allen, Ph.D., Geoffrey Grimm, Ph.D., and Neil Mogge, Ph.D.

Kennedy Center, Federal Correctional Institution - Morgantown, West Virginia

Position: Psychology Intern

Duration: July 2004-June 2005

Duties: $\quad$ Provide assessment and therapeutic services to male inmates at this minimum security federal prison

Supervisors: $\quad$ Edward Baker, Ph.D. and Jeffrey Hammond, Ph.D.

Quin Curtis Center, Department of Psychology, West Virginia University

Position: Student Therapist

Duration: $\quad$ August 2004-July 2005

Duties: $\quad$ Provide therapeutic services (anger management) to community clients

Supervisor: William Fremouw, Ph.D.

Quin Curtis Center, Department of Psychology, West Virginia University

Position: $\quad$ Student Therapist

Duration: $\quad$ August 2003-December 2004

Duties: $\quad$ Provide therapeutic services to community clients

Supervisor: Martin Boone, Ph.D.

\section{Teaching Experience}

\section{Introduction to Psychology}

Position: Graduate Teaching Assistant, Department of Psychology, West Virginia University

Duration: $\quad$ August 2003-May 2004

Duties: $\quad$ Prepare and deliver lectures, manage WebCT grade book, hold office hours

Supervisors: Cindy Anderson, Ph.D. and Jennifer Margrett, Ph.D.

\section{Affiliations}

American Psychological Association

American Psychology-Law Society-Division 41 of APA

Clinical Psychology, Division 12 of APA

Assessment Psychology, Section IX, Clinical Psychology, Division 12, APA 